Research Article

\title{
Evaluation of the Performance Degradation of Hybrid Steel-Polypropylene Fiber Reinforced Concrete under Freezing-Thawing Conditions
}

\author{
Daming Luo, ${ }^{1,2}$ Yan Wang $\mathbb{D}^{1,3}$ and Ditao Niu $\mathbb{D}^{1,2}$ \\ ${ }^{1}$ State Key Laboratory of Green Building in Western China, Xi'an University of Architecture and Technology, Xi'an 710055, China \\ ${ }^{2}$ School of Civil Engineering, Xi'an University of Architecture and Technology, Xi'an 710055, China \\ ${ }^{3}$ College of Materials Science and Engineering, Xi'an University of Architecture and Technology, Xi'an 710055, China
}

Correspondence should be addressed to Yan Wang; wangyanwjx@xauat.edu.cn and Ditao Niu; niuditao@163.com

Received 17 September 2020; Revised 7 November 2020; Accepted 30 November 2020; Published 28 December 2020

Academic Editor: Xun Xi

Copyright (c) 2020 Daming Luo et al. This is an open access article distributed under the Creative Commons Attribution License, which permits unrestricted use, distribution, and reproduction in any medium, provided the original work is properly cited.

The reasonable inclusion of hybrid fibers can leverage the advantages of each kind of fiber and enhance the frost resistance and flexural toughness of concrete. Previous studies on hybrid steel-polypropylene fiber reinforced concrete (HSPFRC) focused primarily on its mechanics instead of its frost resistance. In this work, the compressive strength, splitting tensile strength, mass loss rate, relative dynamic elastic modulus (RDEM), and flexural toughness of HSPFRC after freezing-thawing (F-T) are studied, and the relative importance of each factor affecting the frost resistance of HSPFRC is quantified by using fuzzy rough set theory. The results show that the inclusion of hybrid fibers has a noticeable effect on the frost resistance of HSPFRC after hundreds of F-T cycles and that the effect on the splitting tensile strength is greater than that on the compressive strength. After $500 \mathrm{~F}-\mathrm{T}$ cycles, as the steel fiber (SF) content increases, the compressive strength and splitting tensile strength increase by factors of approximately 5 and 4, respectively, the flexural toughness is strengthened, and the mass loss rate is reduced by more than $90 \%$. The addition of polypropylene fibers (PFs) has a relatively small effect on the strength of HSPFRC but reduces the mass loss of HSPFRC by almost $80 \%$. However, the suitability of the RDEM for evaluating the frost resistance of HSPFRC remains uncertain. Quantified by fuzzy rough set theory, the weights of the factors affecting the frost resistance of HSPFRC are 0.50 (number of F-T cycles) $>0.35$ (SF content) $>0.15$ (PF content), verifying the experimental results.

\section{Introduction}

Fiber reinforced concrete (FRC), a new type of high-strength and tough cementitious material, consists chiefly of a matrix (i.e., mortar or concrete composite) and reinforcing materials (i.e., metal fibers, inorganic nonmetallic fibers, synthetic fiber, or natural organic fibers) [1]. Fibers in concrete composites are chaotically distributed and can bridge cracks, relieve the stress at crack tips, and bear the stress caused by an external load. Moreover, the bonding effect between the fibers and the composite can effectively delay the formation and expansion of cracks, inhibit the accumulation and development of damage, and enhance the FRC service performance [1].

In the last few decades, research on FRC has developed rapidly, focusing mainly on reinforced concrete mixed with steel fibers (SFs) [2, 3], polypropylene fibers (PFs) $[4,5]$, basalt fibers $[6,7]$, carbon fibers $[8,9]$, aramid fibers [10], glass fibers [11], and so on. When properly added and mixed into concrete, SFs can clearly improve the mechanical performance, friction behavior, and fatigue properties of concrete, enhance its toughness and impact resistance, alleviate its crack propagation, and improve its durability [12]. However, SFs agglomerate easily and have a large selfweight, whereas PFs are flammable organic fibers with a low production cost and low tensile strength. The inclusion of PFs can similarly prevent cracks from developing in the composite, effectively improving its impermeability, toughness, and impact resistance [13]; furthermore, PFs do not rust as easily as SFs and thus are more suitable for corrosive environments [14], reflecting the unique 
advantages and development potential of PFs in the field of concrete reinforcement. Therefore, concrete mixed with SFs and PFs is widely employed in highway pavement, bridge decks, airport runways, industrial buildings, hydraulic structures, tunnel linings, and other special structures.

However, the addition of a single type of fiber can improve only certain properties of concrete mixtures, and the improvement of their comprehensive performance is limited [15]. In recent years, the research focus has gradually shifted from traditional FRC with a single fiber type to hybrid fiber reinforced concrete (HFRC) [16-18]. HFRC can utilize the advantages of each fiber with different sizes and shapes, thereby compensating for the deficiencies of concrete materials with a complementary and synergistic effect [19]. SFs with a high elastic modulus have a substantial reinforcing effect but are expensive, while PFs with a low elastic modulus are relatively cheap; therefore, HFRC mixed with the above two fibers may exhibit excellent mechanical performance and a relatively low cost [20].

To better understand the properties of hybrid steelpolypropylene fiber reinforced concrete (HSPFRC), a large number of environmental erosion tests [21] and mechanical tests have been carried out $[20,22]$, and research on HSPFRC has developed from investigating its material properties to studying the mechanical behavior [23] and seismic performance of the concrete components [24]. The proper mixing of SFs and PFs in HSPFRC can improve its compressive, splitting, and flexural capacities [22], effectively alleviate shrinkage cracking [25], and reduce its water absorption and corrosive medium permeability [21, 26]. In cold regions, the occurrence of frost heave in concrete will result in the accumulation of internal damage and even substantial structural deterioration [27]. In this context, appropriate contents of SFs and PFs can have a "positive hybrid effect" and can promote the frost resistance of concrete [26]; however, an excessive fiber content will cause a "negative hybrid effect" [22]. In addition, under different experimental regimes, the mechanical properties of HSPFRC after freezing-thawing (F$\mathrm{T})$ cycles are substantially different from those of ordinary concrete or concrete with a single type of fiber $[5,15]$. Accordingly, it is necessary to further study how SFs and PFs affect the frost resistance of HSPFRC and the degree of their effect.

In view of the above problems, this investigation is performed to evaluate the frost resistance of HSPFRC with different contents of SFs and PFs by quantifying the mass loss rate, relative dynamic elastic modulus (RDEM), compressive strength, and splitting tensile strength. Fuzzy rough set theory will be used to quantify the degrees of influence of the environmental conditions and mixture composition on the frost resistance of HSPFRC. In addition, the flexural toughness of HSPFRC will be evaluated by using the JSCE SF-4 [28], postcrack strength (PCS) [29], and CECS 13-2009 [30] methods, and the applicability of the above three methods will be discussed.

\section{Materials and Methods}

\subsection{Raw Materials}

2.1.1. Cement. The chemical composition and physical properties of the ordinary Portland cement (OPC) used in this study are shown in Tables 1 and 2, respectively. The water-reducing agent involved is a polycarboxylate superplasticizer, the optimum content of which determined by pretesting is $0.50 \%$ of the total weight of the cementitious material.

2.1.2. Aggregates. Crushed stone and river sand are used as coarse aggregate and fine aggregate, respectively. Their physical properties are shown in Table 3.

2.1.3. SFs and PFs. The physical properties and appearance of the SFs and PFs are shown in Table 4 and Figure 1, respectively.

2.1.4. Mixture Proportions. The effects of the fiber types and fiber content on the frost resistance of HSPFRC were taken into account, and the mixture proportions were fixed as shown in Table 5 .

2.2. Specimen Preparation. After several pretests [31], the samples were prepared with the mixing procedures shown in Figure 2.

\subsection{Test Methods}

2.3.1. F-T Testing. The procedures of the test are as follows [32]

(i) After being cured in a moist room for 24 days, the specimens were removed from the chamber and soaked in lime water $\left((20 \pm 2)^{\circ} \mathrm{C}\right)$ for 4 days.

(ii) The specimens were placed into the F-T chamber, and the temperature at the center of the specimens and the temperature of the heat-conducting medium were monitored. Each F-T cycle lasted approximately $6 \mathrm{~h}$, and the temperature measurement system and alternating F-T regime are illustrated in Figure 3.

(iii) After a certain number of F-T cycles, the test was terminated when the mass loss rate reached $5 \%$ or the RDEM dropped to $60 \%$.

\subsubsection{Frost Resistance Index}

(1) Mass Loss Rate

Specimens with dimensions of $100 \mathrm{~mm} \times 100 \mathrm{~mm} \times$ $400 \mathrm{~mm}$ were removed from the F-T chamber after every 25 F-T cycles and toweled dry and weighed by using an electronic scale with a precision of $0.1 \mathrm{~g}$. The mass loss rate $W_{n}$ can be calculated as follows: 
TABLE 1: Chemical composition of the cement (\% wt.).

\begin{tabular}{lccccccccc}
\hline Chemical composition & $\mathrm{CaO}$ & $\mathrm{SiO}_{2}$ & $\mathrm{Al}_{2} \mathrm{O}_{3}$ & $\mathrm{Fe}_{2} \mathrm{O}_{3}$ & $\mathrm{SO}_{3}$ & $\mathrm{MgO}$ & $\mathrm{K}_{2} \mathrm{O}$ & $\mathrm{Na}_{2} \mathrm{O}$ & $\mathrm{LOI}$ \\
\hline Content (\%) & 64.0 & 20.7 & 6.16 & 4.41 & 2.6 & 1.82 & 1.2 & 0.20 & 1.21 \\
\hline
\end{tabular}

TABLe 2: Physical properties of the cement.

\begin{tabular}{lcccccc}
\hline \multicolumn{2}{l}{ Setting time (min) } & Specific gravity & Specific surface $\left(\mathrm{m}^{2} / \mathrm{kg}\right)$ & \multicolumn{2}{c}{$\begin{array}{c}\text { Flexural strength } \\
(\mathrm{MPa})\end{array}$} & $\begin{array}{c}\text { Compressive } \\
\text { strength }(\mathrm{MPa})\end{array}$ \\
\hline Initial & Final & 3.14 & 341 & $3 \mathrm{~d}$ & $28 \mathrm{~d}$ & $3 \mathrm{~d}$ \\
100 & 180 & & & 4.5 & $28 \mathrm{~d}$ \\
\hline
\end{tabular}

TABle 3: Physical properties of the aggregates.

\begin{tabular}{lccccccc}
\hline $\begin{array}{l}\text { Physical } \\
\text { properties }\end{array}$ & $\begin{array}{c}\text { Particle size } \\
(\mathrm{mm})\end{array}$ & $\begin{array}{c}\text { Clay content } \\
(\%)\end{array}$ & $\begin{array}{c}\text { Crush value } \\
(\%)\end{array}$ & $\begin{array}{c}\text { Water absorption } \\
(\%)\end{array}$ & $\begin{array}{c}\text { Bulk density } \\
\left(\mathrm{g} / \mathrm{cm}^{3}\right)\end{array}$ & $\begin{array}{c}\text { Apparent density } \\
\left(\mathrm{g} / \mathrm{cm}^{3}\right)\end{array}$ & $\begin{array}{c}\text { Fineness } \\
\mathrm{modulus}^{3}\end{array}$ \\
\hline $\begin{array}{l}\text { Coarse } \\
\text { aggregate }\end{array}$ & $5-31.5$ & 0.75 & 5.00 & 1.02 & 1.43 & 2.82 & - \\
Fine aggregate & - & 1.00 & - & 1.20 & 1.48 & 2.63 & 2.7 \\
\hline
\end{tabular}

TABle 4: Physical properties of the fibers.

\begin{tabular}{lcccccc}
\hline Fibers & $\begin{array}{c}\text { Diameter } d \\
(\mathrm{~mm})\end{array}$ & $\begin{array}{c}\text { Length } l \\
(\mathrm{~mm})\end{array}$ & $\begin{array}{c}\text { Density } \\
\left(\mathrm{g} / \mathrm{cm}^{3}\right)\end{array}$ & $\begin{array}{c}\text { Tensile strength } \\
(\mathrm{MPa})\end{array}$ & $\begin{array}{c}\text { Tensile elastic modulus } \\
(\mathrm{GPa})\end{array}$ & $\begin{array}{c}\text { Elongation at break } \\
(\%)\end{array}$ \\
\hline $\begin{array}{l}\text { Steel fiber } \\
\text { Polypropylene }\end{array}$ & 0.5 & 30 & 7.8 & 1457 & 475 & 2.6 \\
fiber & 0.035 & 14 & 0.91 & 293 & 3.4 & 35 \\
\hline
\end{tabular}

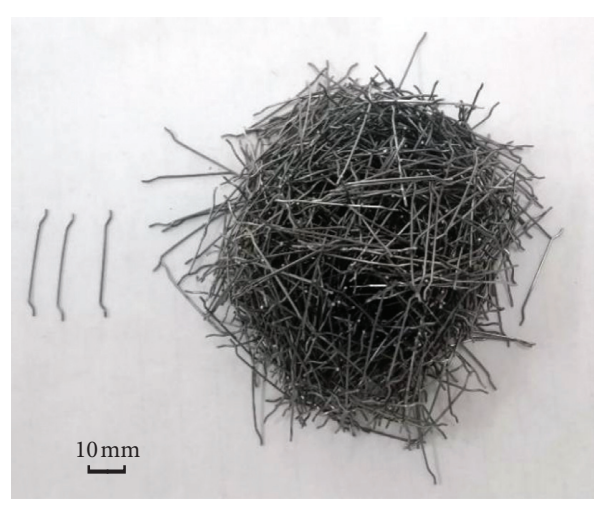

(a)

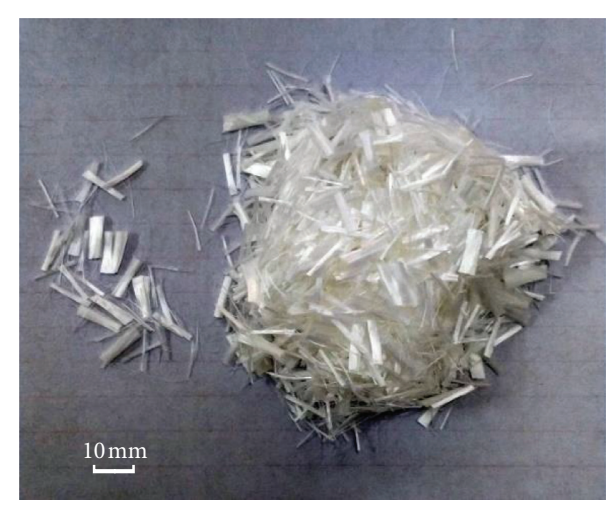

(b)

FIgURE 1: Appearance of the fibers: (a) steel fibers (SFs); (b) polypropylene fibers (PFs).

$$
W_{n}=\frac{m_{0}-m_{n}}{m_{0}} \times 100 \%,
$$

where $m_{0}$ and $m_{n}$ are the specimen mass before and after the F-T cycles in $\mathrm{kg}$, respectively.

(2) RDEM

After every $100 \mathrm{~F}$-T cycles, the specimens were ovendried at $60{ }^{\circ} \mathrm{C}$ until their weight difference fell below $0.1 \mathrm{~g}$ in $24 \mathrm{~h}$. The ultrasonic propagation time of the specimens was measured (Figure 4), and the RDEM $E$ can be calculated as follows:

$$
E=\frac{e_{n}}{e_{0}}=\frac{v_{n}^{2}}{v_{0}^{2}}=\frac{t_{0}^{2}}{t_{n}^{2}} \times 100 \%
$$

where $e_{n}$ and $e_{0}$ are the dynamic elastic modulus after and before the F-T cycles, respectively; $v_{n}$ and $v_{0}$ are the ultrasonic propagation velocity through concrete after and before the F-T cycles $(\mathrm{m} / \mu \mathrm{s})$; and $t_{n}$ and $t_{0}$ are the ultrasonic propagation times after and before the F-T cycles $(\mu \mathrm{s})$, respectively.

(3) Strength loss 
TABLE 5: Mixture proportions of the HSPFRC.

\begin{tabular}{|c|c|c|c|c|c|c|}
\hline \multirow[t]{2}{*}{ Mixture ID } & \multicolumn{4}{|c|}{ Component $\left(\mathrm{kg} / \mathrm{m}^{3}\right)$} & \multicolumn{2}{|c|}{$\begin{array}{l}\text { Fiber volume } \\
\text { fraction }(\%)\end{array}$} \\
\hline & Water & Cement & Coarse aggregate & Fine aggregate & SF & PF \\
\hline R0 & 170 & 447 & 1098 & 732 & - & - \\
\hline S0P0.1 & 170 & 447 & 1098 & 732 & - & 0.1 \\
\hline S0P0.2 & 170 & 447 & 1097 & 731 & - & 0.2 \\
\hline S0.5P0 & 170 & 447 & 1075 & 717 & 0.5 & - \\
\hline S0.5P0.1 & 170 & 447 & 1074 & 717 & 0.5 & 0.1 \\
\hline S0.5P0.2 & 170 & 447 & 1074 & 716 & 0.5 & 0.2 \\
\hline S0.5P0.3 & 170 & 447 & 1073 & 716 & 0.5 & 0.3 \\
\hline S1P0 & 170 & 447 & 1051 & 700 & 1 & - \\
\hline S1P0.1 & 170 & 447 & 1051 & 700 & 1 & 0.1 \\
\hline S1P0.2 & 170 & 447 & 1050 & 701 & 1 & 0.2 \\
\hline $\mathrm{S} 1.5 \mathrm{P} 0$ & 170 & 447 & 1028 & 685 & 1.5 & - \\
\hline S1.5P0.1 & 170 & 447 & 1027 & 685 & 1.5 & 0.1 \\
\hline $\mathrm{S} 1.5 \mathrm{P} 0.2$ & 170 & 447 & 1027 & 685 & 1.5 & 0.2 \\
\hline S2P0.1 & 170 & 447 & 1004 & 669 & 2 & 0.1 \\
\hline
\end{tabular}

Note. R, S or SF, $P$ or PF = reference group, SF, or PF, respectively; and $0,0.1,0.2,0.3,0.5,1,1.5$, and $2=0,0.1 \%, 0.2 \%, 0.3 \%, 0.5 \%, 1 \%, 1.5 \%$, and $2 \%$.

\begin{tabular}{|c|c|c|c|c|c|c|c|c|c|}
\hline \multirow{2}{*}{$\begin{array}{l}\text { Added fine and } \\
\text { coarse aggregate }\end{array}$} & \multicolumn{2}{|l|}{ Stirred } & \multicolumn{3}{|l|}{ Stirred } & \multicolumn{2}{|c|}{ Stirred } & \multicolumn{2}{|l|}{ Stirred } \\
\hline & $\stackrel{\text { for } 30 \mathrm{~s}}{\longrightarrow}$ & $\begin{array}{l}\text { Added } \\
\text { PF }\end{array}$ & $\stackrel{\text { for } 30 \mathrm{~s}}{\longrightarrow}$ & $\mathrm{Ad}$ & $\begin{array}{l}\text { ded } \\
\text { F }\end{array}$ & \begin{tabular}{|l} 
for 30 \\
\end{tabular} & s $\begin{array}{l}\text { Added } \\
\text { cement }\end{array}$ & 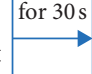 & $\begin{array}{l}\text { Added mixing water with } \\
\text { dissolving superplasticizer }\end{array}$ \\
\hline \multirow[b]{2}{*}{$\begin{array}{c}\text { Ready for } \\
\text { testing }\end{array}$} & & & & & & & & & tirred for $5 \mathrm{~min}$ \\
\hline & \multicolumn{4}{|c|}{$\begin{array}{l}\text { Cured in moisture chamber } \\
\text { temperature: }(20 \pm 2)^{\circ} \mathrm{C} \\
\text { relative humidity: above } 95 \% \text {. }\end{array}$} & \multicolumn{2}{|c|}{ Demolded } & $\begin{array}{l}\text { Sealed } \\
\text { curing } \\
\text { for } 24 \mathrm{~h}\end{array}$ & $\begin{array}{l}\text { Vibrated } \\
\text { for } 20 \mathrm{~s}\end{array}$ & $\begin{array}{l}\text { Poured into molds with } \\
\text { Size: } 100 \times 100 \times 100 \mathrm{~mm}^{3} \\
100 \times 100 \times 400 \mathrm{~mm}^{3}\end{array}$ \\
\hline
\end{tabular}

FIGURE 2: Mixing procedures for sample preparation.

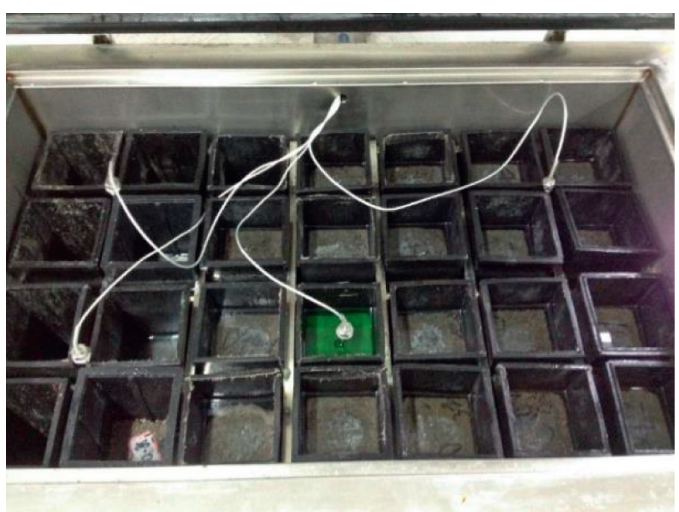

(a)

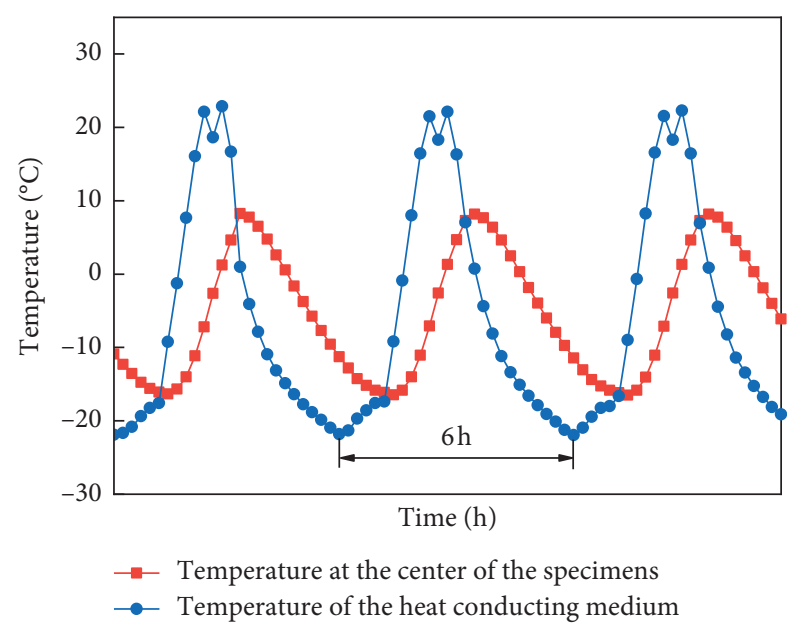

(b)

FIGURE 3: (a) Temperature measurement system and (b) alternating regime of the F-T cycles.

Cubic specimens with dimensions of $100 \mathrm{~mm} \times 100$ $\mathrm{mm} \times 100 \mathrm{~mm}$ were used for the strength loss test. The compressive strength $f_{\text {cn }}$ and splitting tensile strength $f_{\text {tn }}$ can be obtained through formulas (3) and (4), respectively:

$$
\begin{aligned}
& f_{c n}=\frac{P}{A} \times 0.95, \\
& f_{\text {tn }}=\frac{P}{A^{\prime}} \times 0.637 \times 0.85,
\end{aligned}
$$




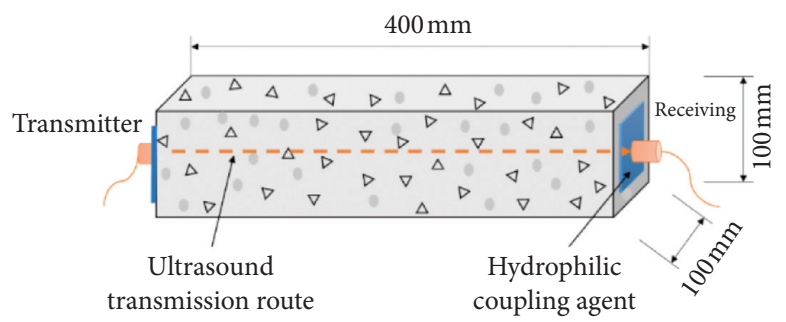

FIgURE 4: Ultrasonic direct-penetration method.

where $P$ is the failure load $(N)$ and $A$ or $A^{\prime}$ is the crosssectional area of the specimen $\left(\mathrm{mm}^{2}\right)$.

The compressive strength loss $Q_{c}$ and splitting tensile strength loss $Q_{t}$ can be calculated by formulas (5) and (6), respectively:

$$
\begin{array}{r}
Q_{c}=\frac{f_{c 0}-f_{c n}}{f_{c 0}} \times 100 \%, \\
Q_{t}=\frac{f_{t 0}-f_{t n}}{f_{t 0}} \times 100 \%,
\end{array}
$$

where $f_{c 0}$ and $f_{t 0}$ are the compressive strength and splitting tensile strength before frost damage (MPa).

\subsubsection{Flexural Toughness Test for HSPFRC. The flexural} toughness of concrete is a measure of the fracture resistance under a flexural load. In many field projects, improving the toughness of concrete is more important than improving the strength. Based on the results of the accelerated F-T test, plain concrete and HSPFRC with a better frost resistance were selected to carry out flexural toughness tests (Figure 5). The flexural toughness of the specimens with dimensions of $100 \mathrm{~mm} \times 100 \mathrm{~mm} \times 400 \mathrm{~mm}$ was evaluated by means of the JSCE SF-4, PCS, and CECS 13-2009 [30] methods.

(1) JSCE SF-4 method

The flexural toughness coefficient suggested by JSCE SF-4 can be calculated as follows:

$$
f_{e}=\frac{\Omega L}{b h^{2} \delta}
$$

where $\delta$ is the midspan deflection $(\mathrm{mm})$ and $\Omega$ is the area enclosed by the load-deflection curve and abscissa corresponding to $\delta=L / 150(\mathrm{~N} \cdot \mathrm{mm})$.

(2) PCS method

The PCS method is similar to the JSCE SF-4 approach. The difference is that different deflections can be chosen, thereby obtaining different PCSs. The PCS can be calculated by formula (8):

$$
\mathrm{PCS}=\frac{\left(E_{\text {post }}\right) \times L}{\left.(L / m)-\delta_{\text {peak }}\right) \times b \times h^{2}},
$$

where $E_{\text {post }}$ is the difference between the area under the load-deflection curve at a deflection of $(\mathrm{L} / \mathrm{m})$ and that at the initial crack deflection $(\mathrm{N} \cdot \mathrm{mm}) ;(L / m)$ is the selected midspan deflection, which is larger than the initial crack deflection, with values of $3 \mathrm{~mm}$, $4 \mathrm{~mm}$, and $5 \mathrm{~mm}$ selected in this study; and $\delta_{\text {peak }}$ is the midspan deflection of the flexural member when it reaches the maximum bearing capacity $(\mathrm{mm})$ and is taken as the initial crack deflection in this study.

(3) CECS 13:2009 method

Similar to the JSCE SF-4 method, the method proposed by the Chinese code CECS 13:2009 mainly evaluates the toughness of concrete according to the energy absorption and flexural toughness ratio. The flexural toughness ratio $R_{e}$ can be calculated as follows [30]:

$$
\begin{gathered}
f_{e}=\frac{\Omega L}{b h^{2} \delta_{k}}, \\
f_{\mathrm{cr}}=\frac{F_{\mathrm{cr}} L}{b h^{2}}, \\
R_{e}=\frac{f_{e}}{f_{\mathrm{cr}}},
\end{gathered}
$$

where $f_{e}$ and $f_{\text {cr }}$ are the equivalent flexural strength and flexural initial crack strength, respectively $(\mathrm{MPa}) ; F_{\mathrm{cr}}$ is the initial crack load $(N)$; and $\Omega_{k}$ and $\delta_{k}$ have the same definitions as $\Omega$ and $\delta$ in equation (7).

\section{Test Results and Discussion}

\subsection{Mass Loss Rate}

3.1.1. Effect of F-T Cycles. The mass loss of HSPFRC is positively associated with the number of F-T cycles (Figure 6). When the total fiber content is relatively small, the maximum mass loss rate reaches $2.97 \%$ (S1P0.2) or $2.43 \%$ (S1P0.1) after the HSPFRC experiences 500 F-T cycles. However, when a relatively large volume of fibers is incorporated, the mass loss rate grows more slowly, and the minimum mass loss rate is below 1\% (S1.5P0.1 and S2P0.1). This may be due to the positive hybrid effect of the fibers in concrete. The two types of fibers are randomly distributed in the concrete and form a dense network, which relieves the stress concentration at the trailing edge of the frost-heaving 


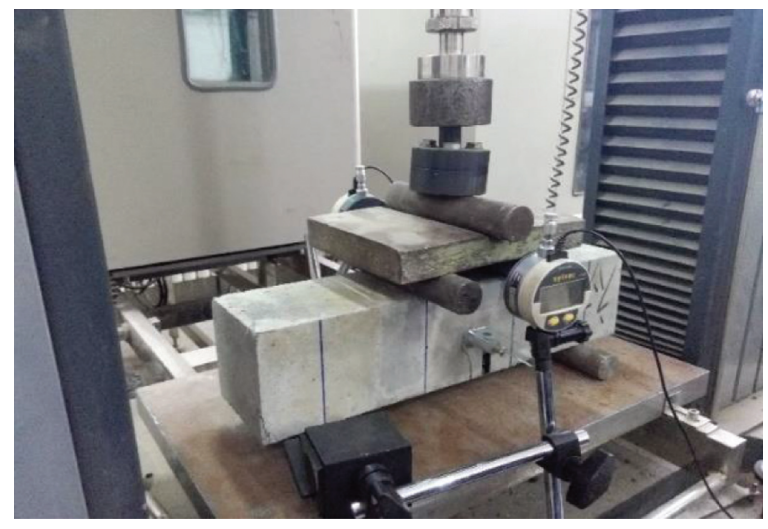

(a)

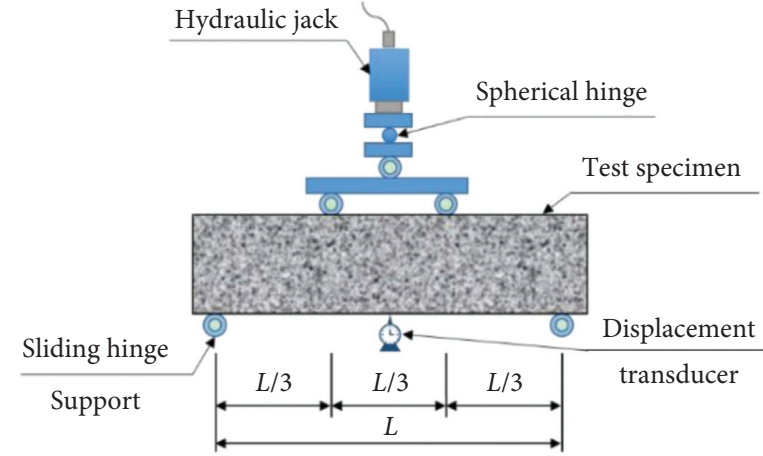

(b)

Figure 5: (a) Setup and (b) schematic diagram of the four-point bending test for the flexural toughness.

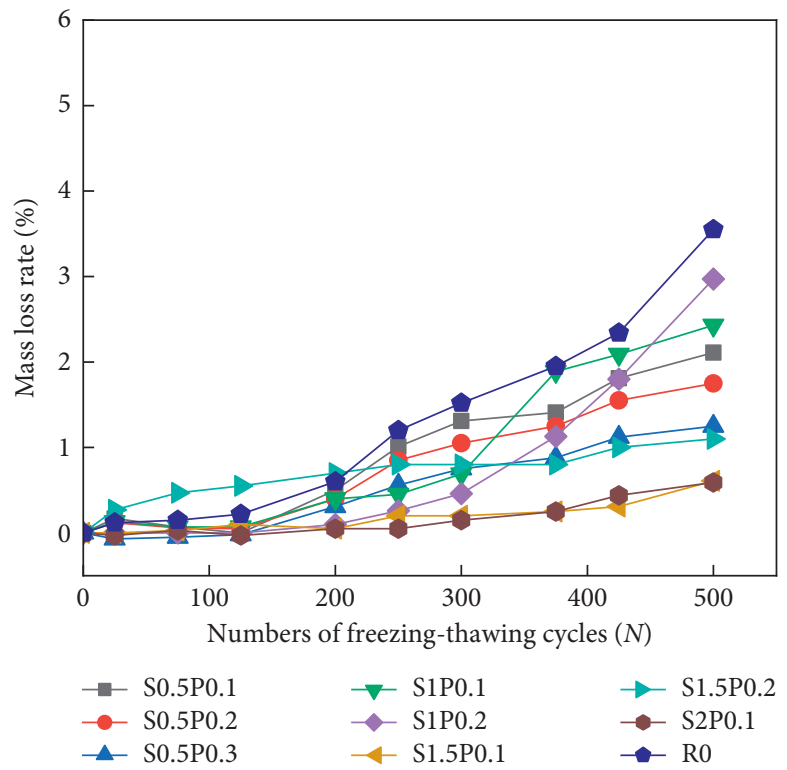

Figure 6: Mass loss rate of HSPFRC.

crack. Moreover, the fibers in the concrete surface layer can effectively bond with cement paste and keep the surface layer from spalling off.

By the end of the test, the relative values of the mass loss rate are ordered as S0.5P0.3 $<$ S0.5P0.1 and $\mathrm{S} 1.5 \mathrm{P} 0.1<\mathrm{S} 1.5 \mathrm{P} 0.2$. The preliminary conclusions indicate that the hybrid effects of both a low SF content mixed with a high PF content and a high SF content mixed with a low PF content are superior to the effect of a single type of fiber.

3.1.2. Effect of PF Content. Figure 7 shows that the mass loss rates of HSPFRC vary with a changing PF content. Regardless of the SF content, an increase in the PF content has a limited effect on the frost resistance when the HSPFRC experiences fewer than 100 F-T attacks. However, after 100 F-T cycles, compared with that of the HSPFRC without PFs, the mass loss rate of the HSPFRC with $0.1 \%$ PFs decreases dramatically, and as the PF content continues to increase, the mass loss rate gradually declines. These findings indicate that hybrid fibers are more effective when the PF content is approximately $0.1 \%$ at the later stage of F-T. Regarding the whole process, compared with that of S0.5P0, the mass loss rate of S0.5P0.3 decreases by $79.5 \%$ after 425 freeze-thaw cycles. PFs, which are relatively fine and lightweight, account for a large quantity per unit volume and can effectively bond with the paste and keep the surface layer of the concrete from spalling off. However, at an excessive PF content, it will be difficult to evenly disperse PFs throughout the concrete, resulting in agglomeration and reducing the reinforcement effect.

3.1.3. Effect of the SF Content. Figure 8 illustrates that the mass loss rate of HSPFRC is negatively correlated with the SF content, and the decrease is more obvious when the $\mathrm{PF}$ content reaches $0.2 \%$, with a maximum reduction of $94.8 \%$ (S1P0.2) after $325 \mathrm{~F}-\mathrm{T}$ cycles. When the SF content exceeds $1.5 \%$, the curves almost coincide, which indicates that the 


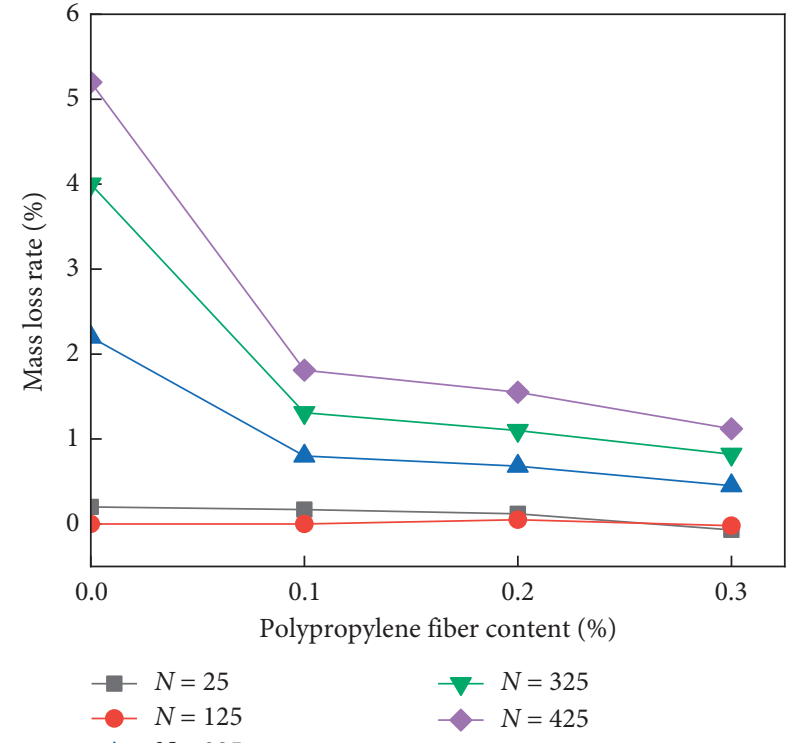

(a)

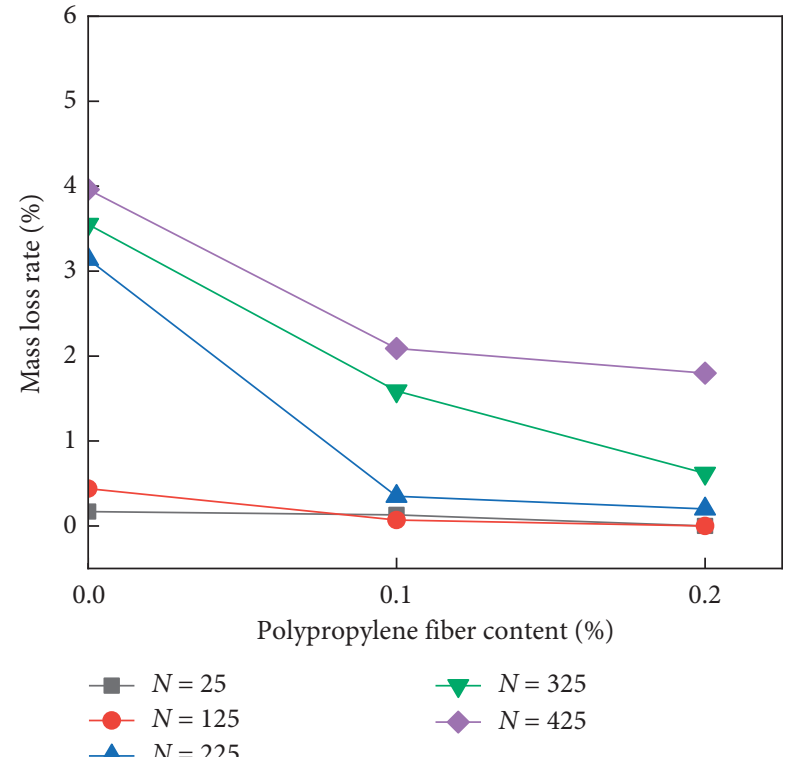

(b)

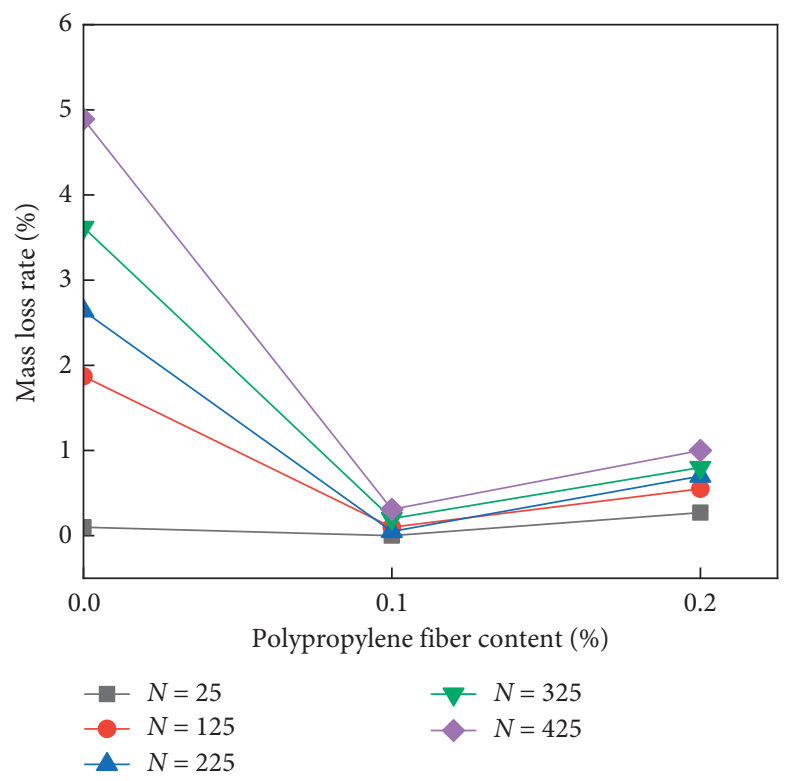

(c)

FIgURE 7: Variation in the mass loss rate of HSPFRC with the PF content: (a) S0.5, (b) S1, and (c) S1.5.

mass loss of HSPFRC under long-term frost attack can be greatly reduced. That is, large amounts of SFs mixed with PFs can greatly enhance the frost resistance of HSPFRC and decrease its mass loss after hundreds of F-T cycles. The existence of PF promotes the function of SF and effectively improves the frost resistance of HSPFRC.

3.2. RDEM. As illustrated in Figure 9, the RDEM of HSPFRC fluctuates with a slight rise under continuous frost attack and that of HSPFRC with a large SF content increases the most. Compared with the decreasing RDEM of ordinary concrete $(R 0)$ after frost attack [33], the RDEM of HSPFRC exhibits the opposite trend. This abnormal phenomenon may be related to the F-T test regimes and the influence of fibers on ultrasonic propagation.

In this study, the RDEM was calculated by longitudinal ultrasonic velocity measurements. After every $100 \mathrm{~F}-\mathrm{T}$ cycles, the specimens were toweled dry, and the ultrasonic wave propagation time was measured. Then, the specimens were soaked for 4 days and placed back into the F-T chamber for further testing. With the accumulation of F-T damage, the unhydrated cement particles on the surfaces of microcracks continued to hydrate, and the hydration products gradually occupied the pores formed during the F-T process and optimized the internal structure of the concrete. In this test, four 


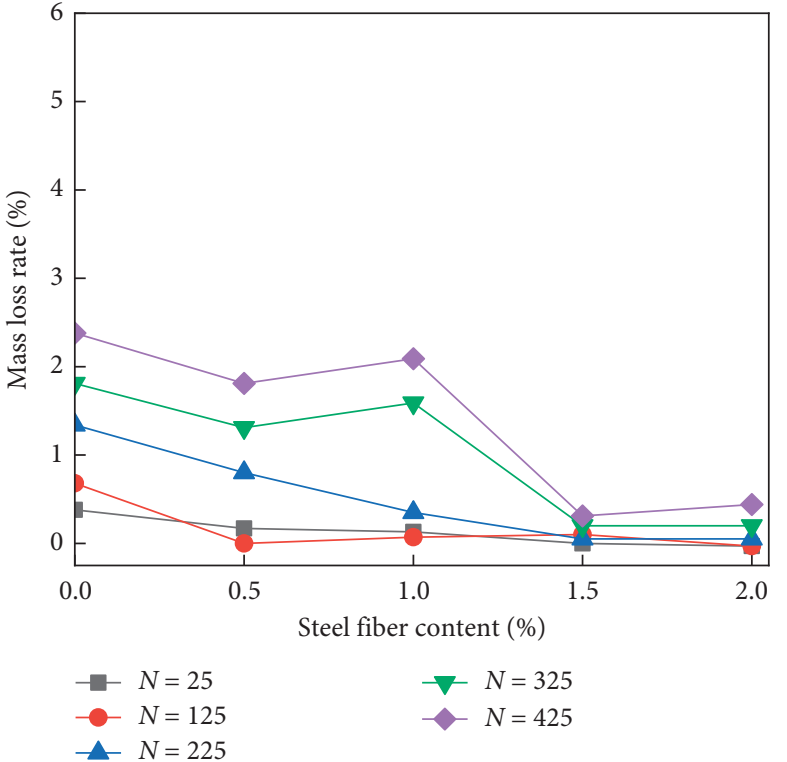

(a)

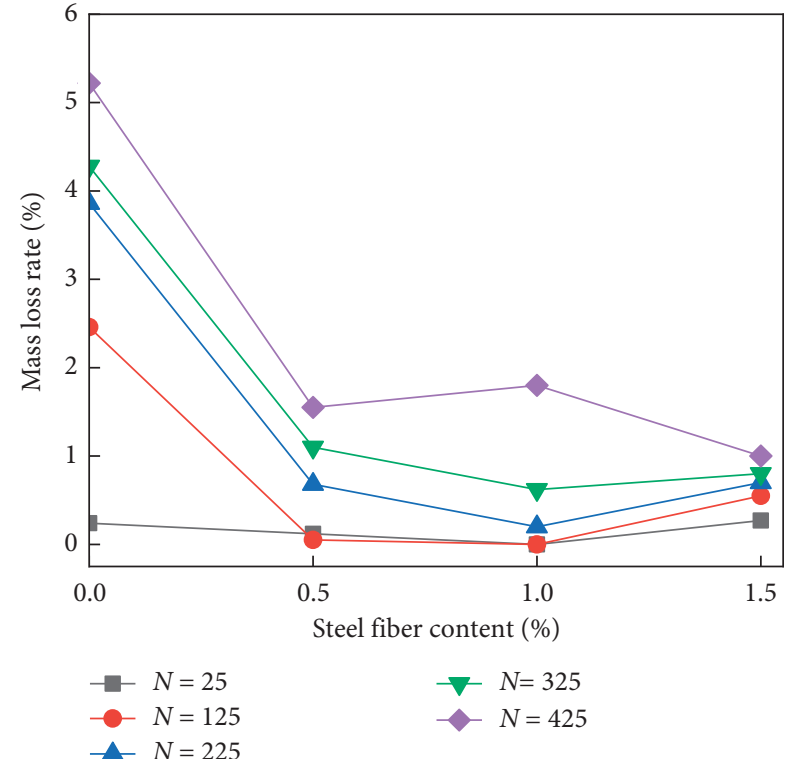

(b)

FIgURE 8: Variation in the mass loss rate of HSPFRC with the SF content: (a) P0.1 and (b) P0.2.

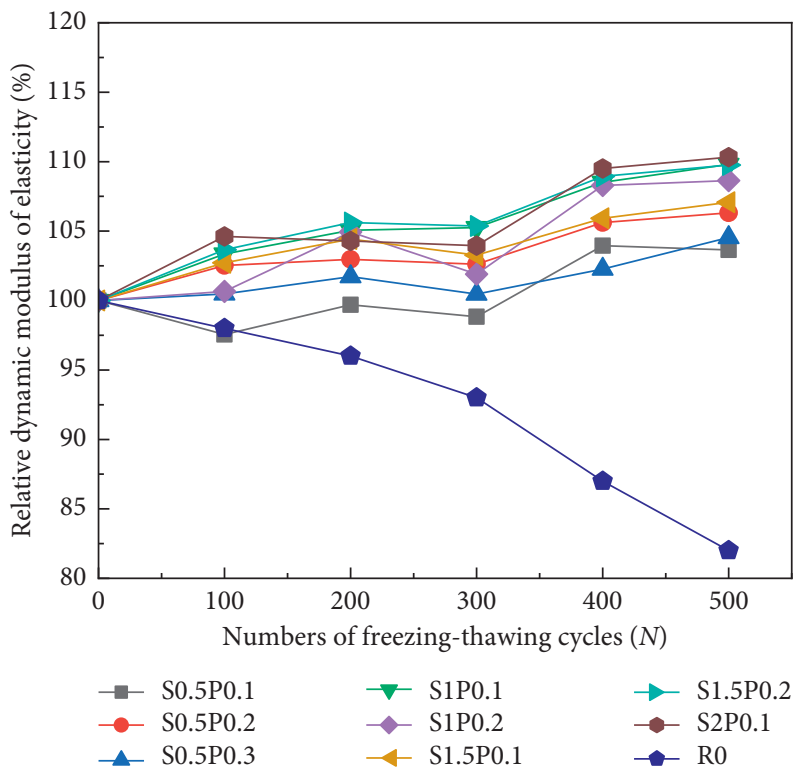

FIgURE 9: Changes in the RDEM of HSPFRC after a certain number of F-T cycles.

days of soaking provided the moisture conditions necessary for self-healing, effectively improving the frost resistance before the next occurrence of damage. The alternation of these soaking and $\mathrm{F}-\mathrm{T}$ processes resulted in irregular fluctuation of the RDEM, which is in accordance with Cao's results [34].

Furthermore, the SFs and PFs in HSPFRC have a great influence on the ultrasonic propagation velocity. In concrete with no fibers, the ultrasonic wave emitted from the transmitter will travel through the matrix, aggregates, and air voids and finally reaches the receiver. However, for HSPFRC, the emitted ultrasonic waves will travel not only through the matrix, aggregates, and air voids but also through the fibers. Hence, because the propagation velocity of ultrasonic waves in SFs is much faster than that in the other components of HSPFRC, the higher the fiber content is, the higher the RDEM of HSPFRC is.

\subsection{Compressive Strength}

3.3.1. Effect of the F-T Cycles. As demonstrated in Figure 10, the compressive strength of HSPFRC decreases with the aggravation of F-T damage. However, by the end of the test, the concrete with a low fiber content, e.g., S0.5P0.1, has a 


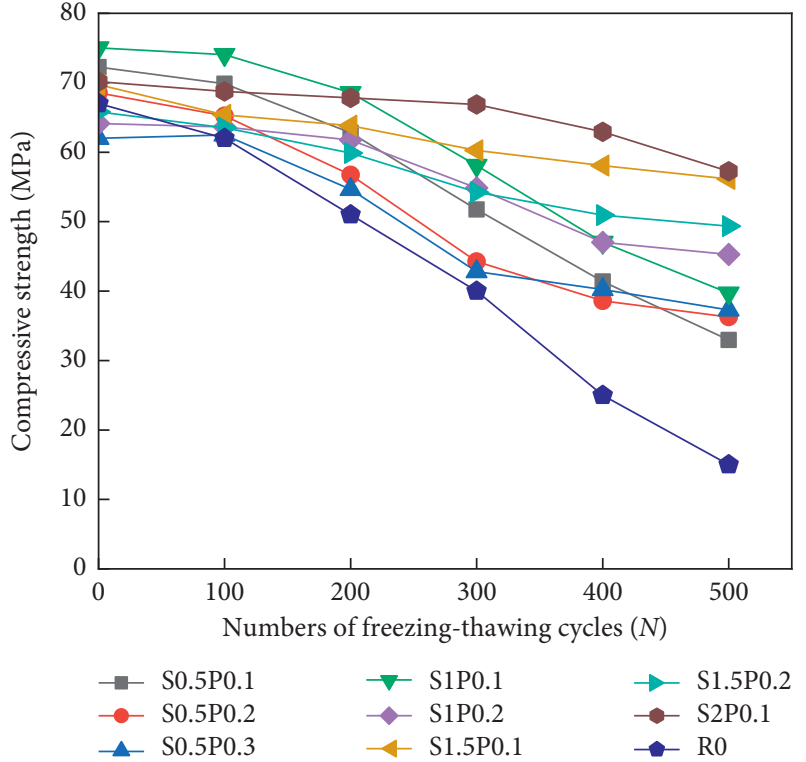

(a)

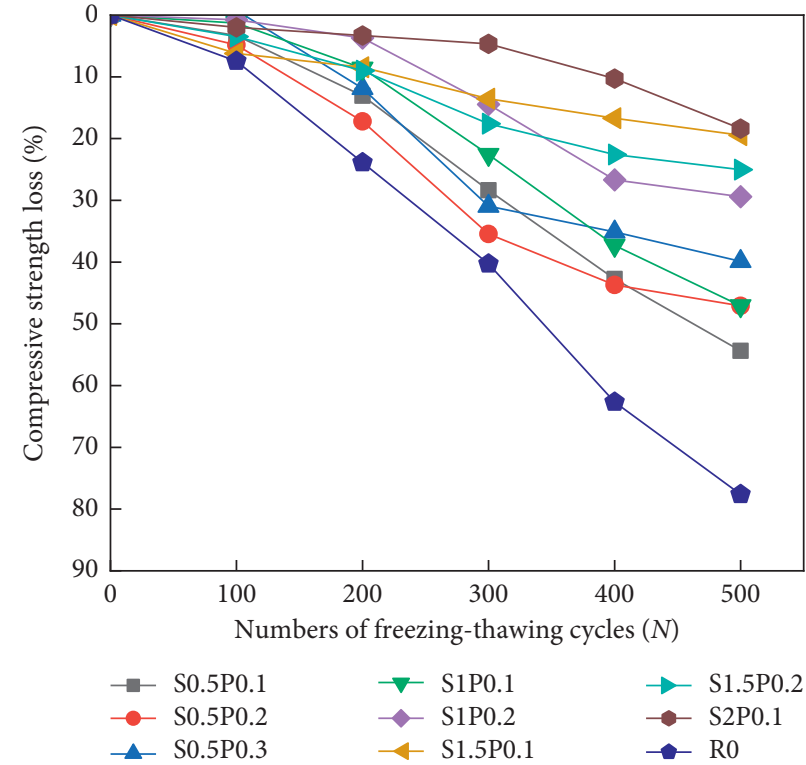

(b)

Figure 10: Compressive strength and loss rate of HSPFRC.

relatively high compressive strength loss of $54.4 \%$, but its residual compressive strength still reaches $32.96 \mathrm{MPa}$. For HSPFRC with a large fiber content, the compressive strength decreases slightly with a compressive strength loss rate of $18.39 \%$ (S2P0.1), and the residual compressive strength is as high as $57.25 \mathrm{MPa}$.

These results demonstrate that HSPFRC can maintain a high compressive strength during the F-T process, and its residual compressive strength is closely associated with the fiber content. Although damage accumulates continuously during the whole F-T process, the network structure formed by SFs and PFs in HSPFRC becomes denser as more hybrid fibers are incorporated, causing a relatively high residual compressive strength after F-T cycles.

3.3.2. Effect of the PF Content. For concrete subjected to fewer than $100 \mathrm{~F}-\mathrm{T}$ cycles, the PF content has a relatively small effect on its frost resistance. After more than $100 \mathrm{~F}-\mathrm{T}$ cycles, for an SF content of $0.5 \%$ (Figure $11(\mathrm{a})$ ), the compressive strength of HSPFRC is stable with a slight decline as the PF content increases; for an SF content exceeding 1\% (Figures 11(b) and 11(c)), the compressive strength of HSPFRC increases when more PFs are incorporated, and this increase is more substantial when the PF content varies from 0 to $0.1 \%$. However, a high content of PFs among the hybrid fibers is unfavorable for achieving a high compressive strength.

An appropriate PF content can improve the frost resistance of HSPFRC in the long term, but an excessive PF content is not conducive to its performance under frost attack. When PFs with a small elastic modulus are randomly distributed in concrete, they can restrain crack propagation under a small stress. Under an external load and internal frost-heaving pressure, the stress of the PFs can easily reach the tensile strength, and the weak interface between the PF and cement paste may also reduce the reinforcing effect $[35,36]$, deteriorating the HSPFRC performance.

3.3.3. Effect of the SF Content. As presented in Figure 12, at the early stage of F-T, the compressive strength of HSPFRC fluctuates slightly as the SF content increases. However, after hundreds of F-T cycles, HSPFRC with a large SF content has a higher compressive strength than that with a small SF content, and this disparity becomes much more obvious when the PF content is relatively small (Figure 12(a)). When this test ends, S2.0P0.1 still has a compressive strength of $57.25 \mathrm{MPa}$, which is 5.81 times that of S0P0.1, indicating that the effect of hybrid fiber inclusion is better when a high SF content is mixed with a low PF content, especially under long-term continuous frost attack. The presented results show that SFs with a high elastic modulus and high tensile strength are likely to effectively inhibit frost-heaving cracks, causing the SF reinforced concrete to bear greater loads and dissipate more energy when subjected to compression. Moreover, due to the high weight of SFs, the number of SFs per unit volume is small, and thus, when a certain amount of SFs are added, the number of SFs across cracks can substantially increase, and the compressive strength can be improved.

\subsection{Splitting Tensile Strength}

3.4.1. Effect of F-T Cycles. Similar to the compressive strength in Figure 10, HSPFRC exhibits a substantial improvement in the splitting tensile strength with an increase in the total content of incorporated fibers (Figure 13). After 500 F-T cycles, the splitting tensile strength of S0.5P0.1 decreases by $55.6 \%$ with a residual splitting tensile strength 


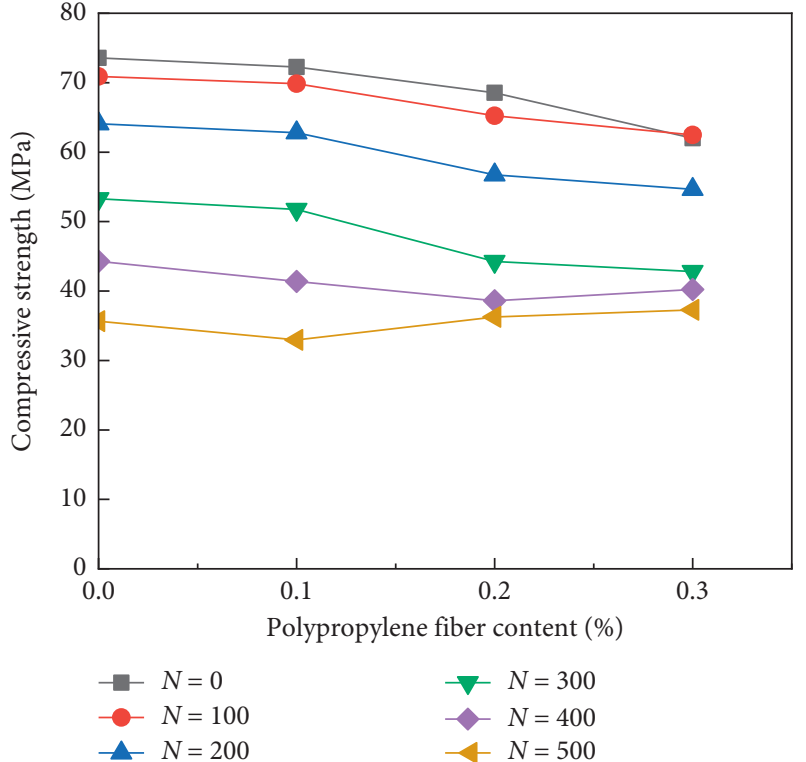

(a)

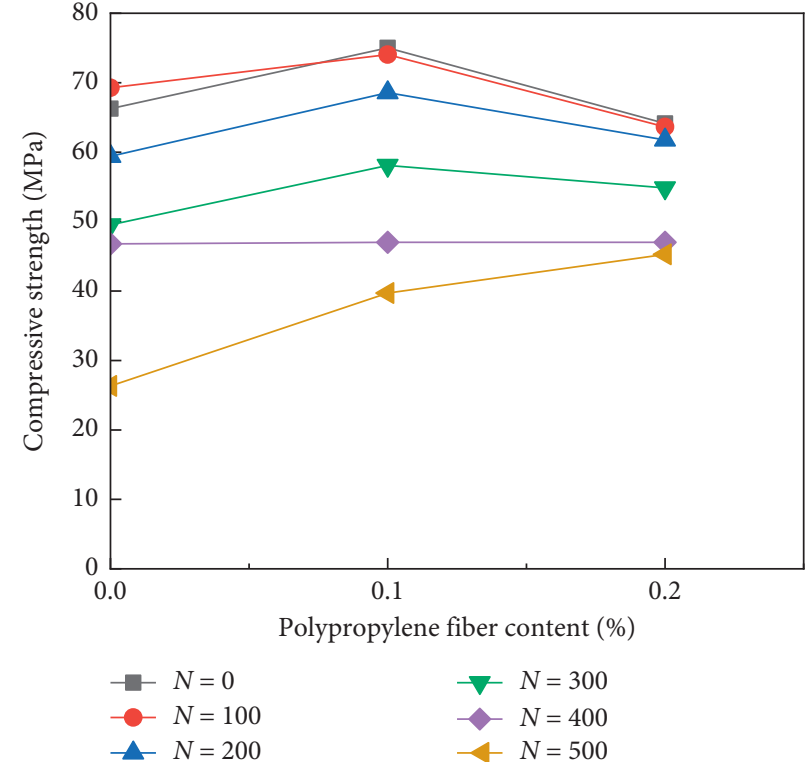

(b)

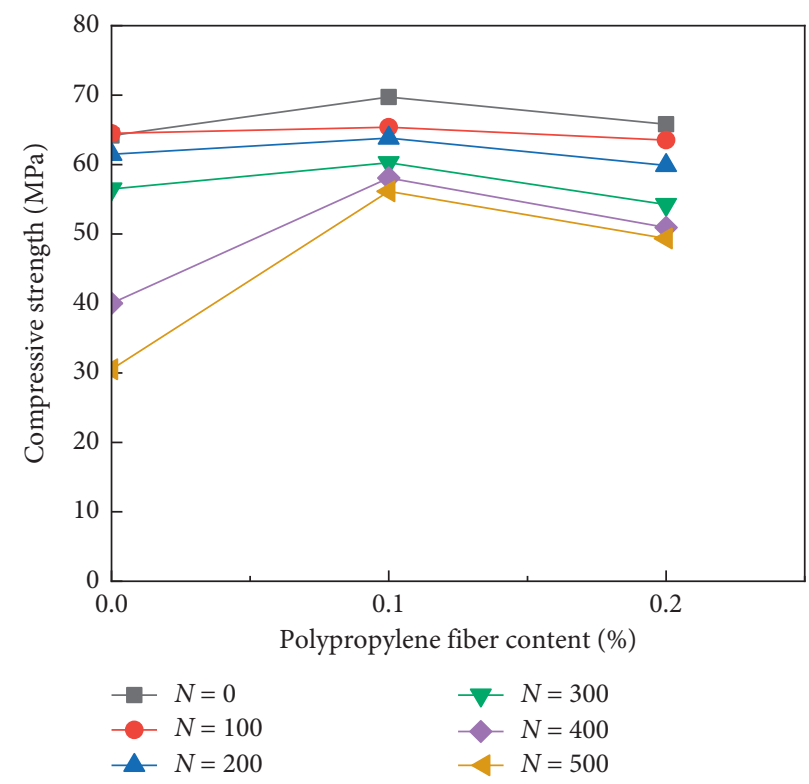

(c)

FIgURE 11: Variation in the compressive strength of HSPFRC with the PF content: (a) S0.5, (b) S1, and (c) S1.5.

of 3.52 MPa. However, for concrete with a high fiber content, the splitting tensile strength decreases more slowly, with a minimum reduction rate of $11.8 \%$ and a residual splitting tensile strength as high as $7.89 \mathrm{MPa}$ (S2P0.1). Due to the difference between the effects of the fiber reinforcement mechanism on the compressive failure and splitting failure of concrete $[5,37]$, the contribution of hybrid fibers to the splitting tensile strength is much greater than that to the compressive strength.
3.4.2. Effect of the PF Content. As illustrated in Figure 14, when the SF content is $0.5 \%$ (Figure $14(\mathrm{a})$ ), the splitting tensile strength of HSPFRC fluctuates slightly within $1.5 \mathrm{MPa}$ as the PF content increases, and when the SF content exceeds 1\% (Figures 14(b) and 14(c)), the splitting tensile strength of HSPFRC slightly increases when the PF content increases. For concrete subjected to long-term F-T (500 cycles), the splitting tensile strength reaches a maximum increment of $49 \%$ when the PF content is $0.2 \%$, which 


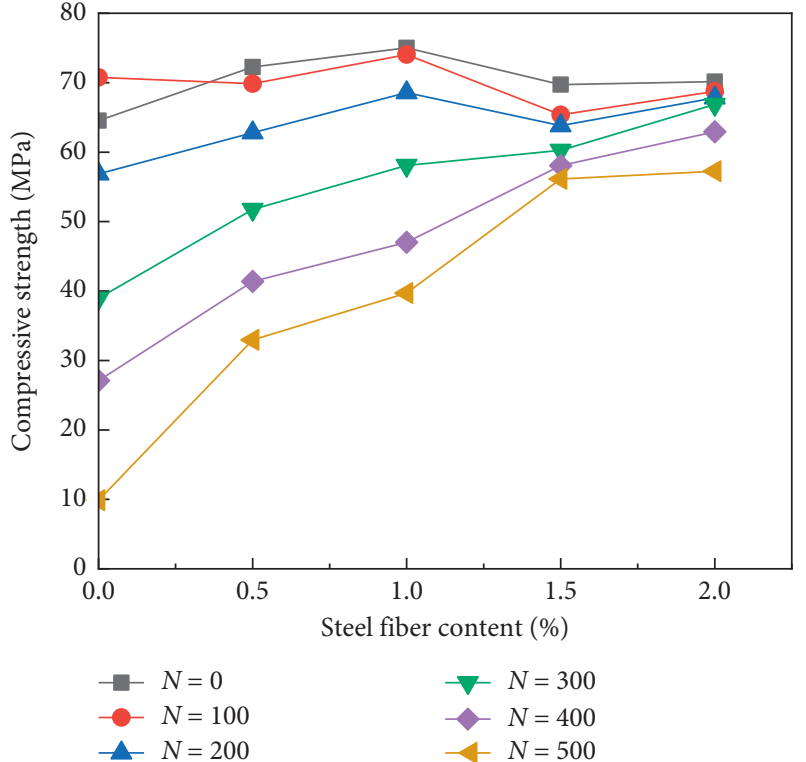

(a)

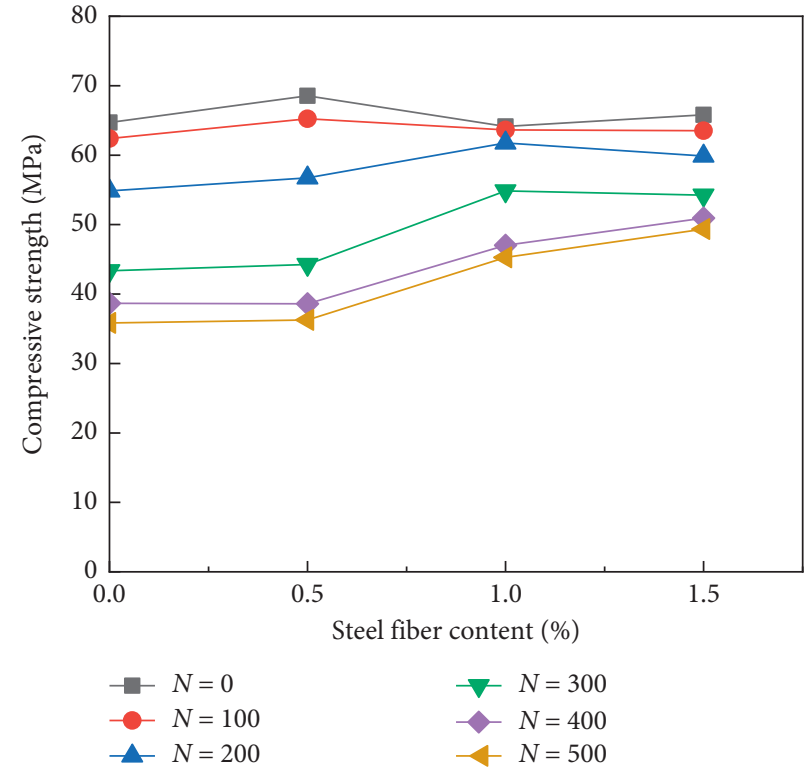

(b)

FIGURE 12: Variation in the compressive strength of HSPFRC with the SF content: (a) P0.1 and (b) P0.2.

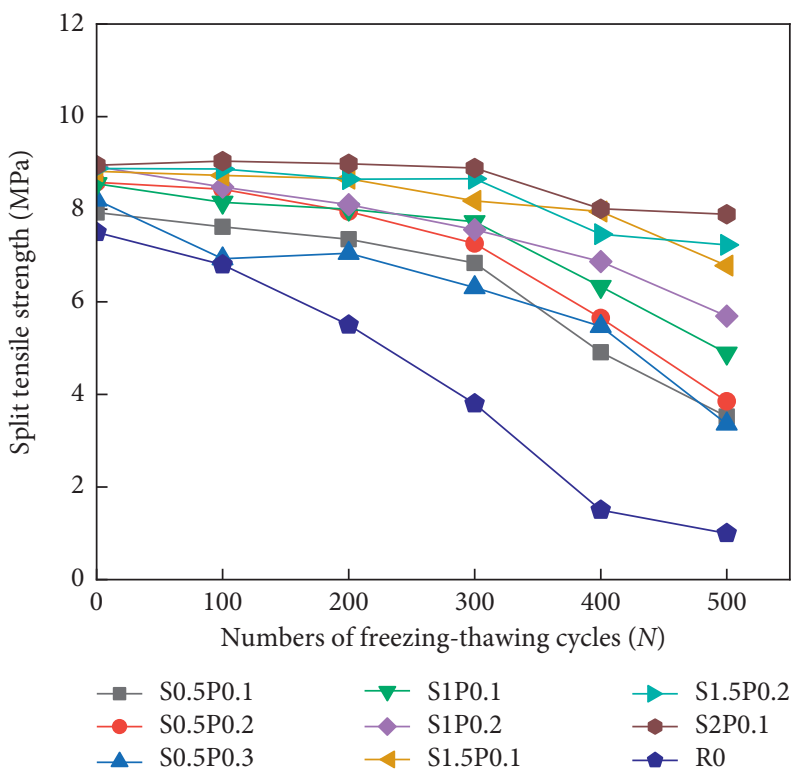

(a)

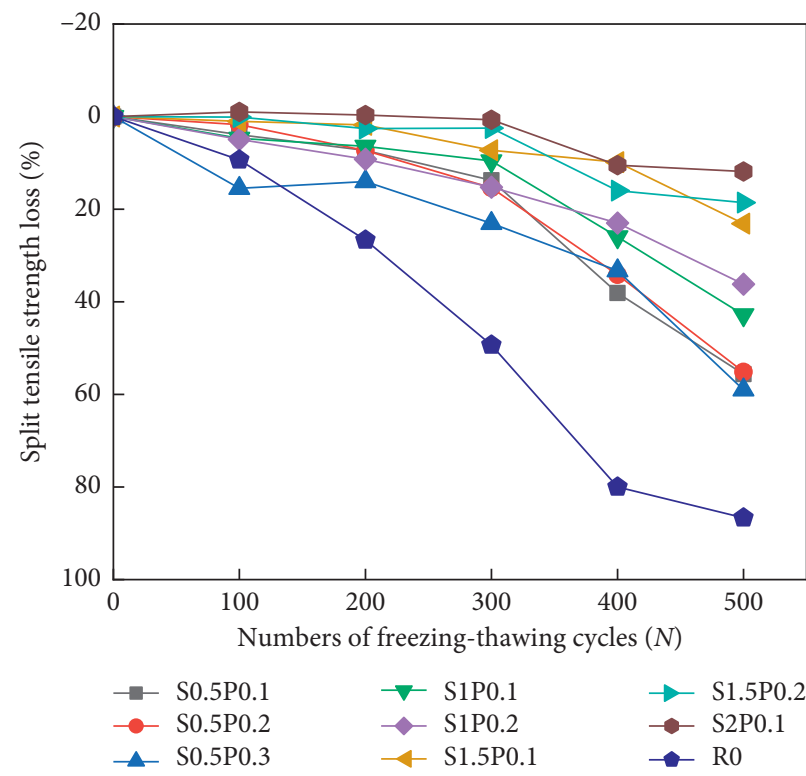

(b)

FIGURE 13: Splitting tensile strength of HSPFRC (a) and its loss (b) after a certain number of F-T cycles.

indicates that SFs and PFs have a substantial synergistic effect on increasing the splitting tensile strength of HSPFRC. Therefore, as the PF content increases, the improvement in the splitting tensile strength will become more remarkable.

3.4.3. Effect of the SF Content. As illustrated in Figure 15, the residual splitting tensile strength of HSPFRC increases dramatically when the SF content increases, which is similar to the trend of the compressive strength shown in Figure 12. When the PF content is $0.1 \%$ (Figure 15(a)), the residual splitting tensile strength of S2P0.1 at the end of the test can be maintained at $7.89 \mathrm{MPa}$, which is 5.03 times that of S0P0.1. When the PF content is $0.2 \%$ (Figure $15(\mathrm{~b})$ ), the splitting tensile strength has a similar variation to the trend plotted in Figure 15(a), but the rate of increase is relatively small.

The test results shown in Figure 15 clearly demonstrate that an increase in the SF content can greatly enhance the splitting tensile strength of HSPFRC, especially when the PF content is 


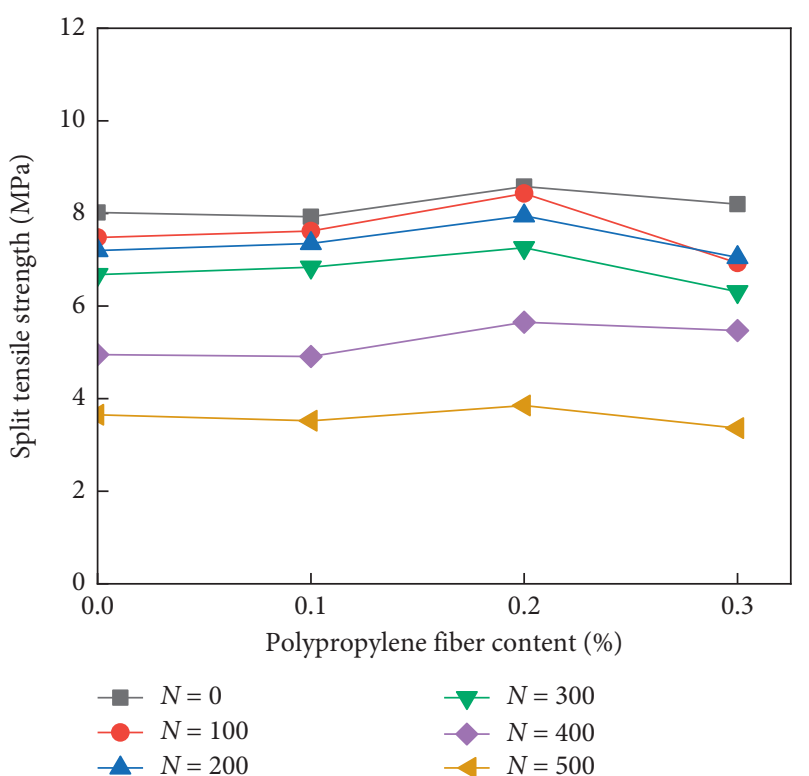

(a)

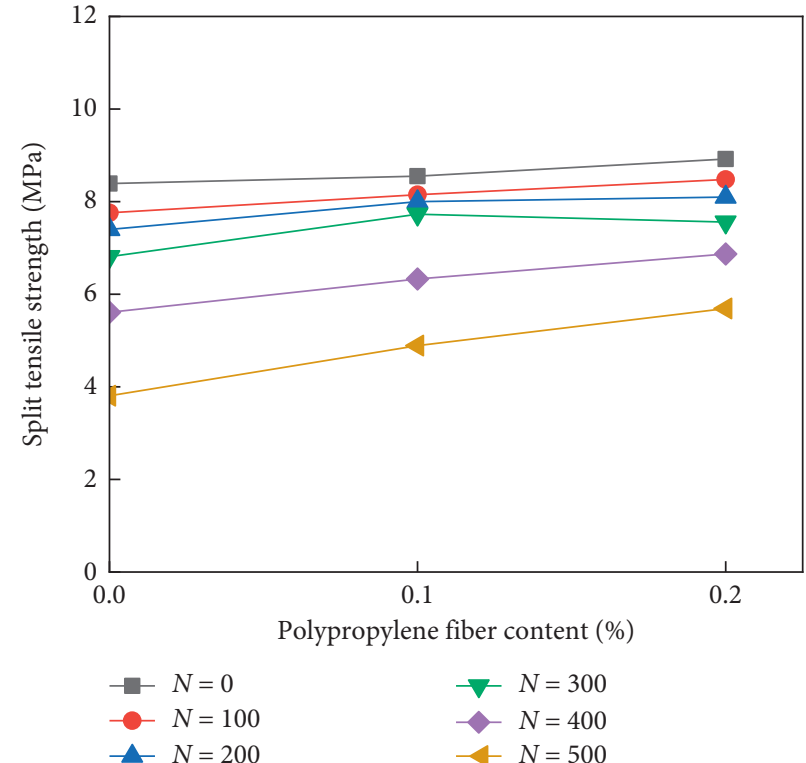

(b)

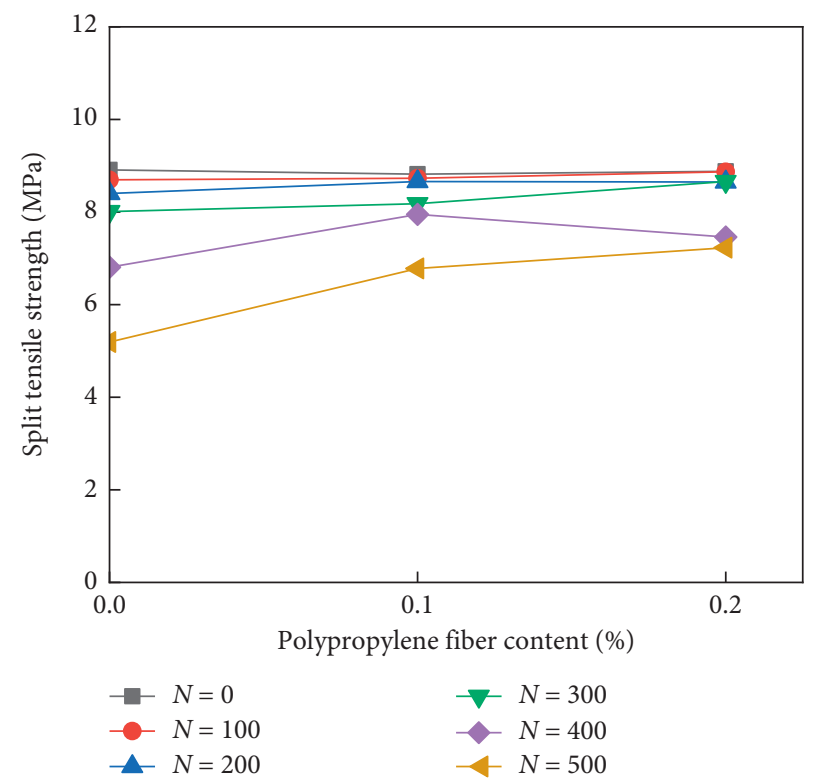

(c)

FIGURE 14: Variation in the splitting tensile strength of HSPFRC with the PF content: (a) S0.5, (b) S1, and (c) S1.5.

small. In addition, combined with Figure 14, an increase in the SF content causes the HSPFRC to exhibit a higher mechanical strength after F-T, while the same effect caused by an increase in the PF content is relatively small, which may be due to the difference in the physical properties between SFs and PFs. During the F-T process, the frost-heaving pressure increases continuously and cracks continue to expand. When the specimens are subjected to external forces, SFs, which have a larger elastic modulus, can restrain the propagation of macrocracks and bear greater tensile stress [38]. However, PFs, which have a smaller elastic modulus, can inhibit the development of microcracks in concrete at the early stage of F-T, while their effect on macrocracks is limited.

\subsection{Flexural Toughness after F-T Cycles}

3.5.1. Flexural Failure Modes of HSPFRC. The load-deflection curve of HSPFRC and its typical flexural failure modes under bending are depicted in Figures 16 and 17, respectively.

For plain concrete (Figure 16(a)), R0, during the initial loading period, the concrete material is in an elastic state, 


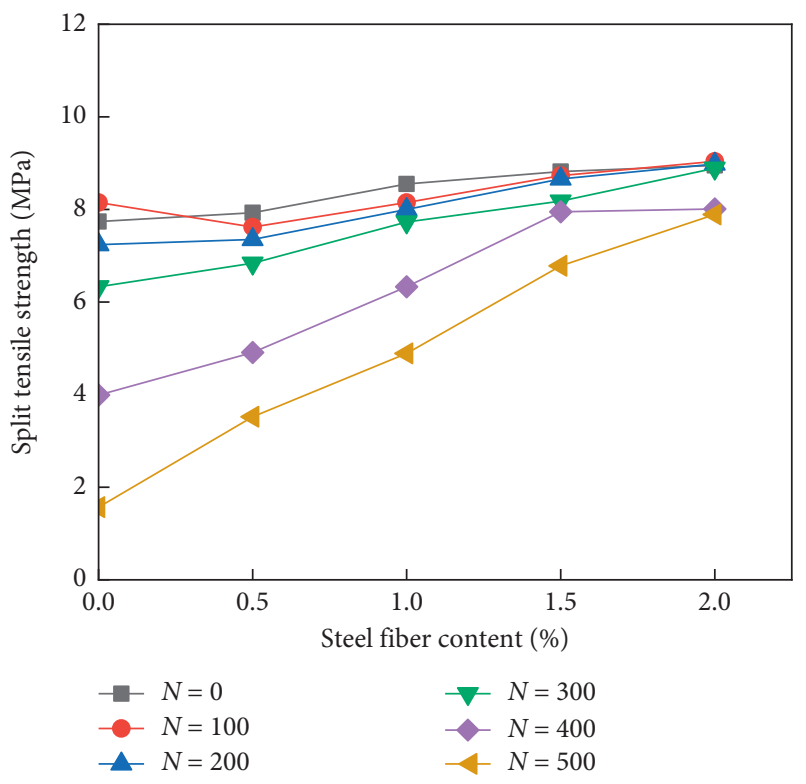

(a)

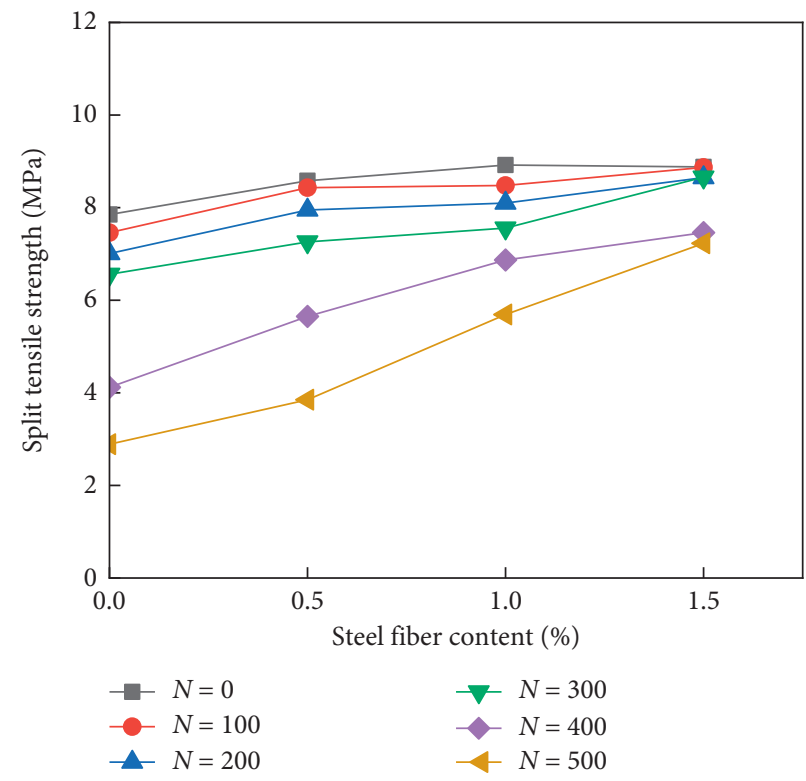

(b)

Figure 15: Variation in the splitting tensile strength of HSPFRC with the SF content: (a) P0.1 and (b) P0.2.

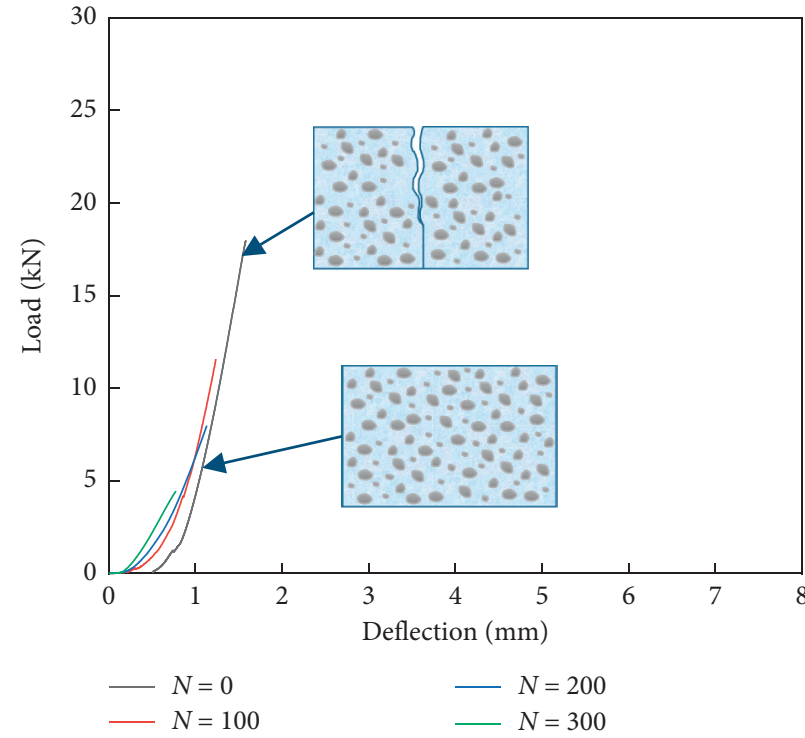

(a)

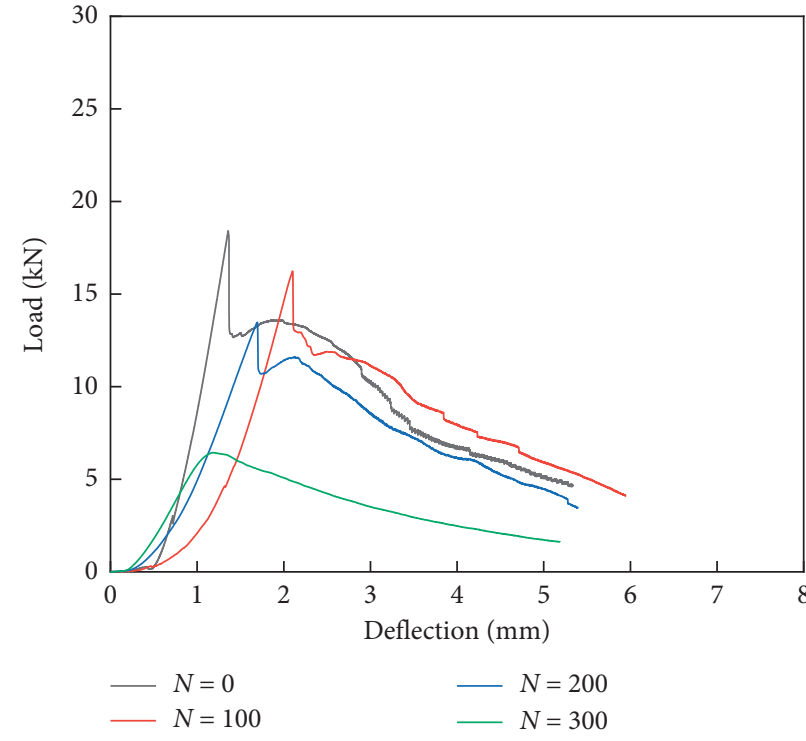

(b)

Figure 16: Continued. 


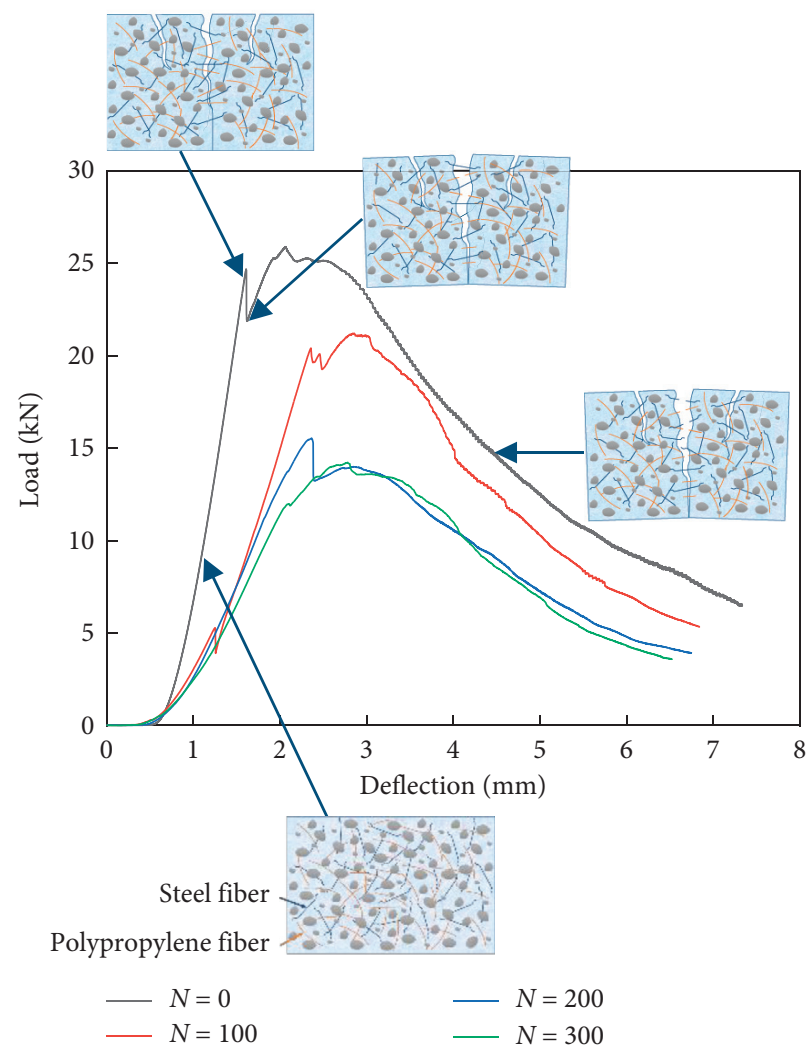

(c)

FIGURE 16: Load-deflection curves of HSPFRC with different fiber contents after certain numbers of F-T cycles: (a) R0, (b) S0.5P0.1, and (c) S1P0.1.

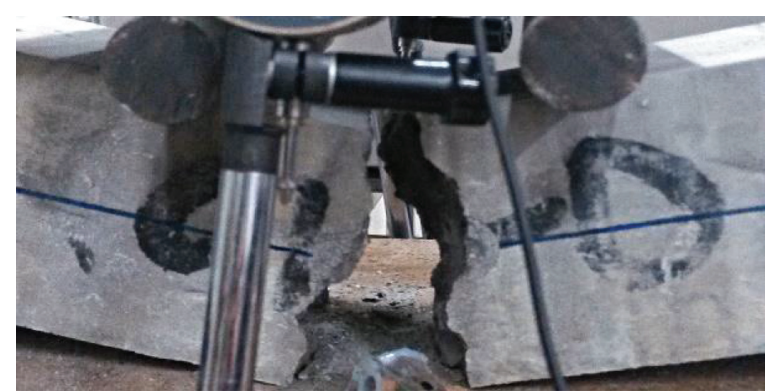

(a)

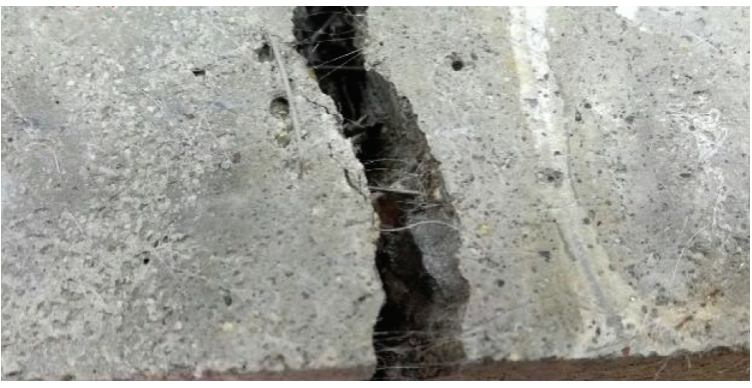

(c)

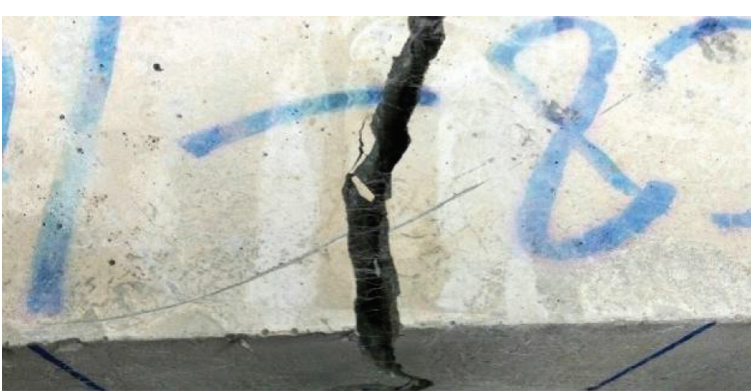

(b)

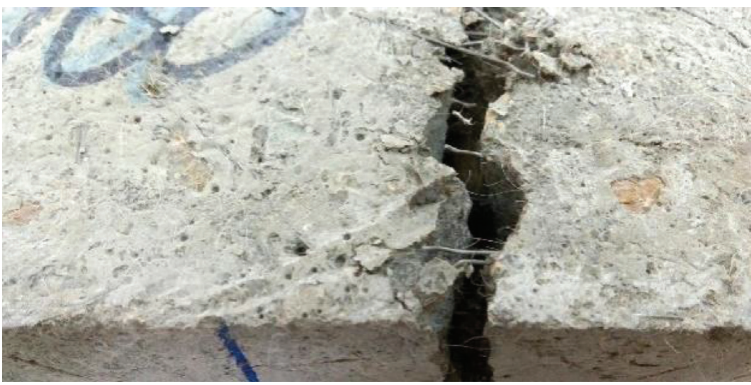

(d)

Figure 17: Continued. 


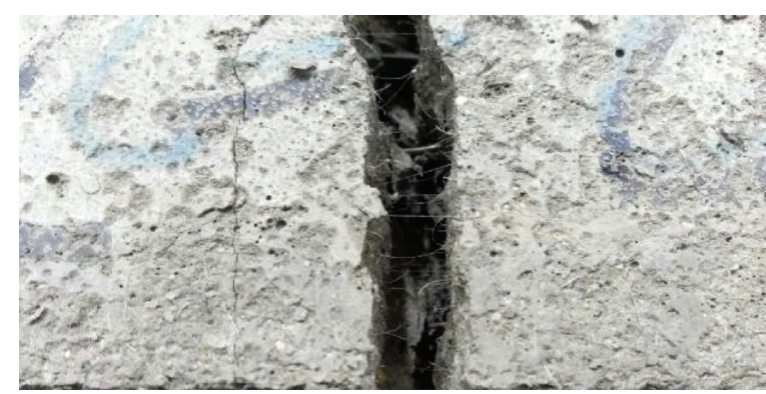

(e)

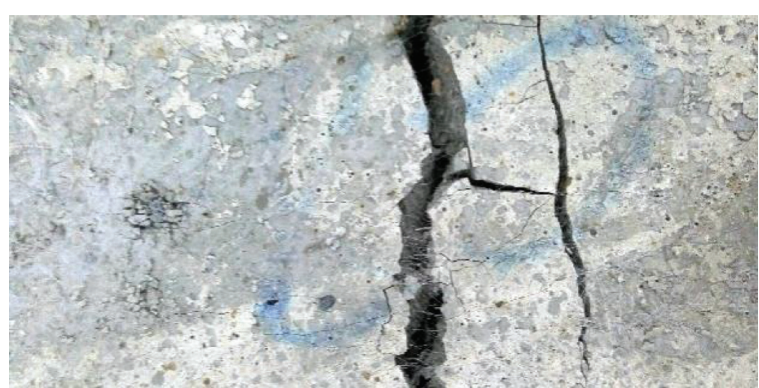

(f)

FIGURE 17: Bending fracture modes of HSPFRC with different fiber contents after different F-T cycles: (a) R0, $N=0$, (b) S0.5P0.1, $N=0$, (c) S0.5P0.1, $N=200$, (d) S1P0.1, $N=200$, (e) S1P0.1, $N=300$, and (f) S1P0.2, $N=300$.

and the load and deflection are approximately linear. As the load increases, the deflection of the concrete beam becomes noticeable, and the stress at the edge of the tensile zone of concrete increases. Upon reaching its ultimate tensile strength, the concrete will crack and immediately be destroyed, showing obvious brittleness.

For HSPFRC (Figures 16(b) and 16(c)), before cracking, the concrete material is in an elastic state, and its stressdeformation relationship is similar to that of plain concrete. The difference is that the fibers and concrete in HSPFRC jointly bear the stress in the concrete beam. After the first crack appears, the tensile stress on the SFs and PFs distributed randomly across the cracks suddenly increases. Because of the bonding effect, the fiber stress at these cracks gradually transfers to the concrete matrix, causing new cracks to propagate. As the load increases, one of the main cracks expands rapidly. The PFs across the cracks are gradually pulled out or broken, diminishing their ability to restrict crack development. Moreover, the tensile stress borne by the PFs is gradually transferred to the SFs. As the load continues to increase, the SFs will be pulled out from the matrix, consuming energy in the process. Thus, the bearing capacity of the HSPFRC increases slightly, showing a secondary peak value. As the load continues, the concrete matrix infused with SFs gradually falls apart, and the small, slender cracks gradually merge into large cracks until the concrete matrix is destroyed.

Compared with plain concrete, HSPFRC has superior toughness. The load-deflection curves of S1P0.1 (Figure 10(c)) are much broader with a quicker rising behavior and a gentler descending section than those of S0.5P0.1 (Figure 10(b)). That is, the incorporated SFs can dramatically enhance the ultimate bearing capacity and flexural toughness of HSPFRC. With an increase in the number of F-T cycles, the load-deflection curves tend to flatten, indicating that the cumulative damage caused by frost attack will reduce the toughness of HSPFRC.

\subsubsection{Flexural Toughness of HSPFRC}

(1) JSCE flexural toughness coefficient

According to JSCE SF-4 [28], the initial crack deflection in this study is taken as $2 \mathrm{~mm}$, and the flexural toughness coefficients of S0.5P0.1 and S1P0.1 are calculated and shown as follows.

Table 6 shows that the flexural toughness coefficient of S1P0.1 tends to decrease and that of S0.5P0.1 fluctuates during the F-T process, which is obviously inconsistent with the test results. This may be due to the initial crack deflection of HSPFRC, which is larger than the value of L/150 recommended in JSCE SF-4. Accordingly, the JSCE flexural toughness coefficient $f_{\mathrm{e}}$ ' is recalculated by taking $\mathrm{L} / 100$ as the initial crack deflection, as shown in Table 7.

From Table 7, the flexural toughness coefficients of S0.5P0.1 and S1P0.1 show a decreasing trend after F-T cycles, and the value of the latter is generally higher than that of the former, indicating that the toughness of HSPFRC is reduced after frost attack and that the toughness of concrete is improved by the inclusion of SFs. This finding is more in accordance with the experimental results than with the values listed in Table 6. The threshold of L/150 recommended by JSCE SF-4 was determined based on a large number of field engineering projects, but it is obviously not suitable for HSPFRC. Therefore, for HSPFRC with a high initial crack deflection and large final deformation, the author suggests that the average stress corresponding to a midspan deflection of $L / 100$ can be defined as the flexural toughness coefficient.

(2) PCS method

In this study, the PCS is calculated by taking $3 \mathrm{~mm}$, $4 \mathrm{~mm}$, and $5 \mathrm{~mm}$ as the small deflection, medium deflection, and large deflection, respectively, as shown in Table 8.

Table 8 shows that the PCSs of S0.5P0.1 and S1P0.1 decrease after F-T cycles, and the PCS of S1P0.1 is generally higher than that of S0.5P0.1 at any deflection, indicating that SFs are beneficial for improving the flexural toughness of HSPFRC. Moreover, both S0.5P0.1 and S1P0.1 reach their maximum PCS at medium deflection $(4 \mathrm{~mm})$, indicating that the toughening effect of fibers is substantial. Compared with the value in Table 7 , the 
TABLE 6: Flexural toughness coefficient of HSPFRC $f_{\mathrm{e}}(\mathrm{MPa})$.

\begin{tabular}{lcccc}
\hline \multirow{2}{*}{ Mixture ID } & \multicolumn{4}{c}{ F-T cycles } \\
& 0 & 100 & 200 & 300 \\
\hline S0.5P0.1 & 2.40 & 1.17 & 1.71 & 1.26 \\
S1P0.1 & 2.99 & 1.32 & 1.24 & 1.09 \\
\hline
\end{tabular}

TABLE 7: Flexural toughness coefficient of HSPFRC $f_{\mathrm{e}}$ (MPa).

\begin{tabular}{lcccc}
\hline \multirow{2}{*}{ Mixture ID } & \multicolumn{4}{c}{ F-T cycles } \\
& 0 & 100 & 200 & 300 \\
\hline S0.5P0.1 & 2.81 & 2.06 & 2.16 & 1.23 \\
S1P0.1 & 4.47 & 2.83 & 2.22 & 2.05 \\
\hline
\end{tabular}

TABLE 8: PCS of HSPFRC with different deformations (MPa).

\begin{tabular}{llcccc}
\hline \multirow{2}{*}{ Mixture ID } & \multicolumn{4}{c}{ F-T cycles } \\
& & 0 & 100 & 200 & 300 \\
\hline \multirow{3}{*}{ S0.5P0.1 } & PCS-3 & 3.91 & 3.74 & 2.05 & 1.49 \\
& PCS-4 & 3.91 & 4.36 & 3.58 & 1.50 \\
& PCS-5 & 2.87 & 2.82 & 1.95 & 1.10 \\
\hline \multirow{3}{*}{ S1P0.1 } & PCS-3 & 7.36 & 6.14 & 4.11 & 5.28 \\
& PCS-4 & 7.87 & 8.02 & 5.92 & 7.42 \\
& PCS-5 & 6.07 & 5.01 & 3.41 & 3.42 \\
\hline
\end{tabular}

Note. PCS-3, PCS-4, and PCS-5 represent the PCSs corresponding to deflections of $3 \mathrm{~mm}, 4 \mathrm{~mm}$, and $5 \mathrm{~mm}$, respectively.

value of PCS-3 in Table 8 is generally higher. Although both calculation methods obtain an equivalent strength, the JSCE SF-4 method considers the interaction effect of fibers and the matrix on improving the flexural strength, while the PCS method ignores the interaction effect and considers only the improvement of fibers after cracking.

(3) CECS 13: 2009 method.

According to CECS 13: 2009 [30], the midspan deflection is taken as $L / 150$, and the flexural toughness ratio $R_{e}=f_{e} / f_{\text {cr }}$ is shown in Table 9 .

The flexural toughness ratios of S1P0.1 and S0.5P0.1 fluctuate during the F-T test, which disagrees with the test results. Taking the midspan deflection as $L / 100$, the calculated flexural toughness ratio is also inconsistent with the test results. These results mean that it remains difficult to accurately evaluate the flexibility of HSPFRC with CECS 13: 2009, the improved JSCE SF-4 method.

3.5.3. Applicability of Toughness Evaluation Methods for HSPFRC. In the present work, the flexural toughness of HSPFRC is evaluated by using three commonly used methods. The improved JSCE flexural toughness coefficient and the PCS method are more suitable for HSPFRC than the CECS 13: 2009 method. However, the primary JSCE flexural toughness coefficient cannot accurately evaluate the performance of concrete before and after cracking, while the PCS method is a good supplement to evaluating the performance of concrete and can evaluate the flexural toughness of concrete beams with different midspan deflections. Nevertheless, although the PCS can reflect the stress level of HSPFRC to some extent, it is inappropriate to ignore the performance of the concrete before reaching its peak value [39]. In contrast, the Chinese standard CECS 13: 2009, which is based on JSCE SF-4 and ASTM 1018, cannot avoid the problems caused by the selection of the initial crack deflection of ASTM 1018 and thus is not suitable for the analysis index of this test.

3.6. Analysis of the Importance of the Factors Affecting the Frost Resistance of HSPFRC. The significance of both the environmental conditions and the concrete composition on the frost resistance of HSPFRC are quantitatively described in this section by using fuzzy rough set theory.

3.6.1. Fuzzy Cluster Analysis. Dynamic cluster analysis based on the fuzzy equivalence relation is used to describe the uncertainty in the F-T test results. In this study, let variable universe $\mathbf{X}=\left\{\mathbf{x}_{1}, \mathbf{x}_{2}, \ldots, \mathbf{x}_{i}, \ldots, \mathbf{x}_{n}\right\}$ represent all the specimens after F-T cycles, and each specimen $\mathbf{x}_{i}=\left\{\mathbf{x}_{i 1}, \mathbf{x}_{i 2}, \ldots, \mathbf{x}_{i m}\right\}$ has $m$ parameters affecting the frost resistance of HSPFRC after suffering frost damage. The dynamic cluster analysis can be performed as follows [40, 41]:

Step 1. Standardize the measured data by the standard deviation transformation:

$$
\begin{aligned}
& x_{i j}^{\prime}=\frac{x_{i j}-\overline{x_{j}}}{s_{j}}, \\
& \overline{x_{j}}=\frac{1}{n} \sum_{i=1}^{n} x_{i j}, \\
& s_{j}=\sqrt{\frac{1}{n} \sum_{i=1}^{n}\left(x_{i j}-\overline{x_{j}}\right)^{2},}
\end{aligned}
$$

where and $s_{j}$ are the average and standard deviation of $x_{i j}$, respectively, and $i=1,2, \ldots, n$ and $j=1,2, \ldots, m$.

Step 2. Use the Euler distance method to determine the similarity coefficient among each test sample $r_{i j}=\mathbf{R}\left(x_{i}\right.$, $x_{j}$ ) and establish the fuzzy similarity matrix $\mathbf{R}$ :

$$
r_{i j}=1-c \cdot \sqrt{\sum_{k=1}^{m}\left(x_{i k}-x_{j k}\right)^{2},} \quad 0 \leq r_{i j} \leq 1 .
$$

Step 3. Use the square transform method to establish the fuzzy equivalent matrix $\mathbf{R}^{*}$. Square transform 
method: $\mathbf{R} \longrightarrow \mathbf{R}^{2} \longrightarrow \mathbf{R}^{4} \longrightarrow \ldots \longrightarrow \mathbf{R}^{2 \mathbf{k}}$ until $\mathbf{R}^{2 \mathbf{k}}=\mathbf{R}^{\mathbf{k}}$, and $\mathbf{R}^{\mathbf{k}}$ is the fuzzy equivalent matrix $\mathbf{R}^{*}$.

Step 4. Choose different confidence levels $\lambda \in[0,1]$ and gradually merge the rows and columns of the fuzzy equivalent matrix $\mathbf{R}^{*}$ obtained in step 3 by using the $\mathbf{F}$ statistic value to obtain the dynamic clustering results [40]:

$$
\begin{aligned}
\mathbf{F} & =\frac{\left(\sum_{j=1}^{r}\left(n_{j}\left\|\overline{\mathbf{x}}^{(j)}-\overline{\mathbf{x}}\right\|^{2}\right) /(r-1)\right)}{\sum_{j=1}^{r} \sum_{i=1}^{n_{j}}\left(\left(\left\|\mathbf{x}_{i}^{(j)}-\overline{\mathbf{x}}^{(j)}\right\|^{2}\right) /(n-r)\right)}, \\
\overline{\mathbf{x}} & =\left(\bar{x}_{1}, \bar{x}_{2}, \ldots, \bar{x}_{k}, \ldots, \bar{x}_{m}\right), \\
\overline{\mathbf{x}}^{(j)} & =\left(\bar{x}_{1}^{(j)}, \bar{x}_{2}^{(j)}, \ldots, \bar{x}_{k}^{(j)}, \ldots, \bar{x}_{m}^{(j)}\right), \overline{\mathbf{x}}_{k}^{(j)}=\frac{1}{n_{j}} \sum_{i=1}^{n_{j}} x_{i k}^{(j)},
\end{aligned}
$$

where $\overline{\mathbf{x}}$ and $\overline{\mathbf{x}}^{(j)}$ are the normal vectors of the sample space and the $j^{\text {th }}$ cluster, respectively, and $\bar{x}_{k}^{(j)}$ is the mean value of the $k^{\text {th }}$ factor that influences the frost resistance of HSPFRC.

3.6.2. Rough Set. In the present work, the weight of each influencing factor affecting the frost resistance of HSPFRC is calculated by rough set theory [42].

(1) Information system

Let $\mathbf{S}=(\mathbf{U}, \mathbf{A}, \mathbf{V}, f)$ be the information system. $\boldsymbol{U}$ represents the collection of specimens, $\mathbf{A}=\mathbf{C} \cup \mathbf{D}$ is the collection of attributes, in which $\mathbf{C}$ is a conditional attribute set and $\mathbf{D}$ is a decision attribute set, $\mathbf{C} \cap \mathbf{D}=\varphi$, and $\mathbf{V}$ is the set of attribute values.

(2) Upper and lower approximations

Let $\mathbf{P}$ and $\mathbf{Q}$ be fuzzy relations on sets $X$ and $\mathbf{Y}$, respectively; let $\mathbf{R} \subseteq \mathbf{X Y}$ signify random boundary conditions on $\mathbf{X Y}$, and let $\mathbf{I}=\mathbf{P R}$ be the product of fuzzy relations. Then, the I-upper approximation and $\mathbf{I}$-lower approximation of $\mathbf{R}$ are as follows:

$$
\begin{aligned}
& \mathbf{I}^{-}(\mathbf{R})=\{(x, y) \in \mathbf{X Y}: \mathbf{I}((\mathbf{X}, \mathbf{Y})) \cap \mathbf{R} \neq \phi\}, \\
& \mathbf{I}_{-}(\mathbf{R})=\{(x, y) \in \mathbf{X Y}: \mathbf{I}((\mathbf{X}, \mathbf{Y})) \subseteq \mathbf{R}\} .
\end{aligned}
$$

Let $\mathbf{B N}_{\mathbf{I}}(\mathbf{R})$ be the region of the boundary of $\mathbf{R}$, which can be obtained by the difference between the upper approximation and lower approximation:

$$
\mathbf{B N}_{\mathbf{I}}(\mathbf{R})=\mathbf{I}^{-}(\mathbf{R})-\mathbf{I}_{-}(\mathbf{R}) \text {. }
$$

(3) Indiscernible relation
TABLE 9: Flexural toughness ratio $\left(R_{e}\right)$ of HSPFRC.

\begin{tabular}{lcccc}
\hline \multirow{2}{*}{ Mixture ID } & \multicolumn{4}{c}{ F-T cycles } \\
& 0 & 100 & 200 & 300 \\
\hline S0.5P0.1 & 0.61 & 0.24 & 0.51 & 0.65 \\
S1P0.1 & 0.41 & 0.22 & 0.27 & 0.26 \\
\hline
\end{tabular}

Let $\mathbf{P}$ be a subset of $\mathbf{C}$; then, the indiscernible relation IND $(\mathbf{P})$ is as follows:

$\operatorname{IND}(\mathbf{P})=\{(x, y) \in \mathbf{U} \times \mathbf{U} \mid, \quad \forall a \in \mathbf{P}, f(x, a)=f(y, a)\}$,

where $f(x, a)$ represents the value of $x \in \mathbf{U}$ with respect to attribute $a$.

(4) Significance of the attributes

Let $\mathbf{P}$ and $\mathbf{Q}$ be subsets of $\mathbf{C}$ and $\mathbf{D}$, respectively. The dependence of knowledge $\mathbf{Q}$ on knowledge $\mathbf{P}$ is as follows:

$$
K=\gamma_{\mathbf{P}}(\mathbf{Q})=\frac{\left|\operatorname{POS}_{\mathbf{P}}(\mathbf{Q})\right|}{|\mathbf{U}|}
$$

where $\operatorname{POS}_{\mathbf{P}}(\mathbf{Q})=\mathbf{P}_{-}(\mathbf{Q})$ and $\left|P O S_{\mathbf{P}}(\mathbf{Q})\right|$ and $|\mathbf{U}|$ are cardinalities of $P O S_{\mathbf{P}}(\mathbf{Q})$ and $\mathbf{U}$, respectively. The significance of the attribute subset $c_{i} \subseteq \mathbf{C}$ with respect to $\mathbf{D}$ is expressed as follows:

$$
\operatorname{SGF}\left(c_{i}, \mathbf{C}, \mathbf{D}\right)=\gamma_{\mathbf{C}}(\mathbf{D})-\gamma_{\mathbf{C}\left\{c_{i}\right\}}(\mathbf{D}),
$$

where $\operatorname{SGF}\left(c_{i}, \mathbf{C}, \mathbf{D}\right)$ represents the significance of $c_{i}$ to $\mathbf{C}$. The greater the significance of the influencing factor is, the greater the impact on the frost resistance of concrete is.

3.6.3. Significance of the Factors Affecting the Frost Resistance of HSPFRC. Twenty-four groups of specimens with 8 mixture proportions are selected as $\mathbf{U} . \mathbf{C}=\left\{c_{1}, c_{2}, c_{3}\right\}$ includes the annual F-T cycles, SF content, and PF content. To better distinguish the data and reduce the size of the data matrix, the numbers of F-T cycles are 200, 400, and 500. The splitting tensile strength of HSPFRC can effectively reflect the strengthening mechanism of hybrid fibers after F-T to a certain extent. Therefore, the splitting tensile strength loss rate after F-T is taken as the decision attribute set $\mathbf{D}=\left\{d_{1}\right\}$, as shown in Table 10.

(1) Establish the fuzzy equivalent matrix $\mathbf{R}^{*}$

The raw data matrix comprising the influencing factors and test results through step 1 of fuzzy cluster analysis is standardized. Then, the similarity matrix $\mathbf{R}$ 
TABLe 10: Collection of the attributes of HSPFRC specimens after frost attack.

\begin{tabular}{|c|c|c|c|c|}
\hline \multirow{2}{*}{ Sample ID } & \multicolumn{3}{|c|}{ Conditional attribute: factors affecting frost resistance } & \multirow{2}{*}{ Decision attribute: splitting tensile strength loss rate (\%) } \\
\hline & F-T cycles & SF content $(\%)$ & PF content $(\%)$ & \\
\hline S0.5P0.1 & 200 & 0.5 & 0.1 & 7.31 \\
\hline S0.5P0.1 & 400 & 0.5 & 0.1 & 38.08 \\
\hline S0.5P0.1 & 500 & 0.5 & 0.1 & 55.61 \\
\hline S0.5P0.2 & 200 & 0.5 & 0.2 & 7.34 \\
\hline S0.5P0.2 & 400 & 0.5 & 0.2 & 34.15 \\
\hline S0.5P0.2 & 500 & 0.5 & 0.2 & 55.13 \\
\hline S0.5P0.3 & 200 & 0.5 & 0.3 & 14.02 \\
\hline S0.5P0.3 & 400 & 0.5 & 0.3 & 33.29 \\
\hline S0.5P0.3 & 500 & 0.5 & 0.3 & 59.02 \\
\hline S1P0.1 & 200 & 1 & 0.1 & 6.43 \\
\hline S1P0.1 & 400 & 1 & 0.1 & 25.96 \\
\hline S1P0.1 & 500 & 1 & 0.1 & 42.81 \\
\hline S1P0.2 & 200 & 1 & 0.2 & 9.19 \\
\hline S1P0.2 & 400 & 1 & 0.2 & 22.98 \\
\hline S1P0.2 & 500 & 1 & 0.2 & 36.21 \\
\hline S1.5P0.1 & 200 & 1.5 & 0.1 & 1.81 \\
\hline S1.5P0.1 & 400 & 1.5 & 0.1 & 9.86 \\
\hline S1.5P0.1 & 500 & 1.5 & 0.1 & 23.13 \\
\hline S1.5P0.2 & 200 & 1.5 & 0.2 & 2.59 \\
\hline S1.5P0.2 & 400 & 1.5 & 0.2 & 15.99 \\
\hline S1.5P0.2 & 500 & 1.5 & 0.2 & 18.58 \\
\hline S2P0.1 & 200 & 2 & 0.1 & -0.34 \\
\hline S2P0.1 & 400 & 2 & 0.1 & 10.50 \\
\hline S2P0.1 & 500 & 2 & 0.1 & 11.84 \\
\hline $\bar{x}_{k}$ & 366.67 & 1.06 & 0.16 & 22.56 \\
\hline $\bar{s}_{k}$ & 124.72 & 0.53 & 0.07 & 17.55 \\
\hline
\end{tabular}

is established by using equation (13) in step 2 , and $\mathbf{R}^{*}$ is constructed through step 3.

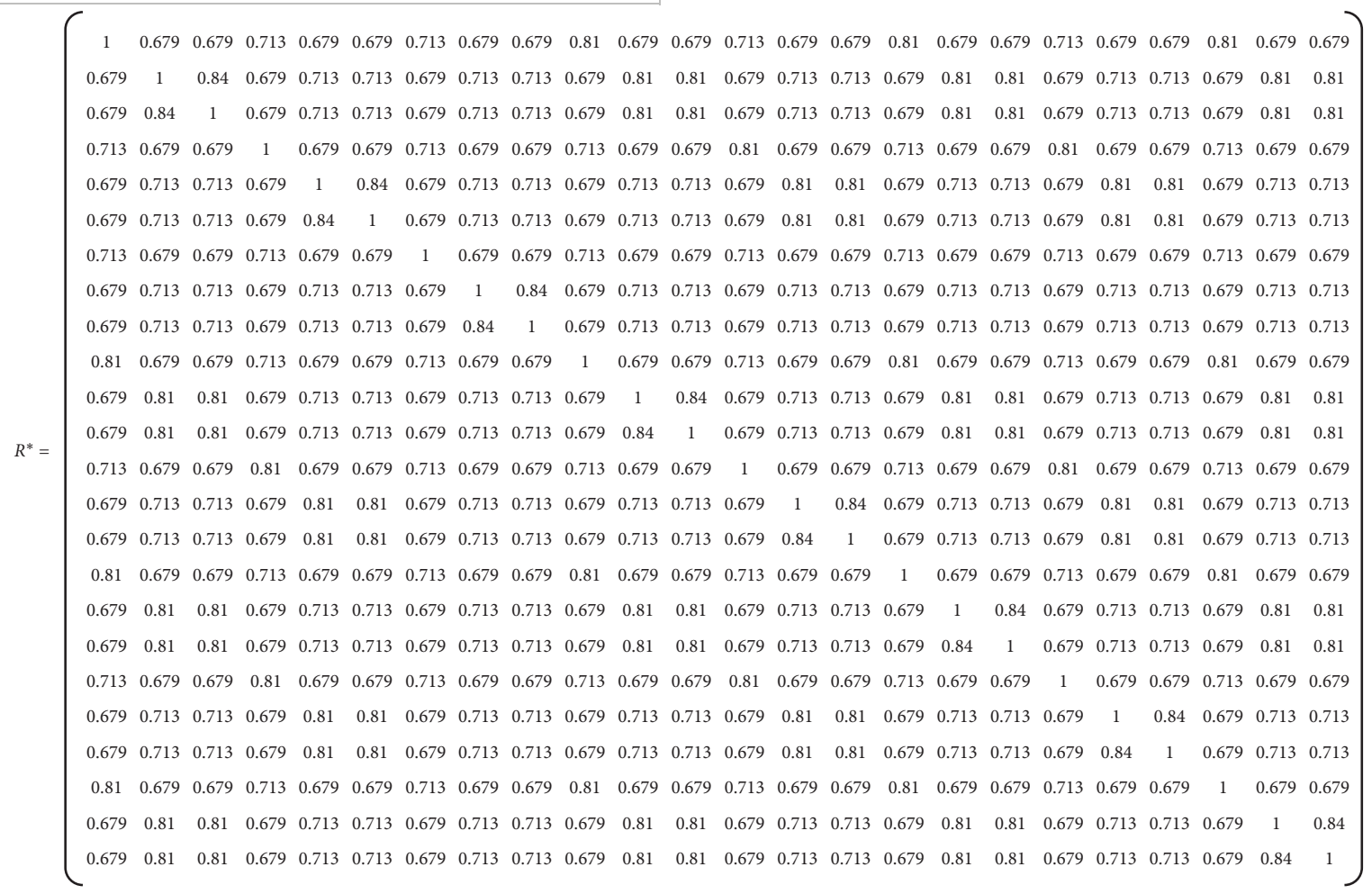


Equation (14) is used to determine $\lambda=0.84$, and then the specimens are classified based on the fuzzy equivalence matrix $R^{*}$ through step 4 . The best classifications of the influencing factors and the splitting tensile strength loss rate are as follows:

U/IND $(C)=\{\{1\},\{2,3\},\{4\},\{5,6\},\{7\},\{8,9\},\{10\}$, $\{11,12\},\{13\},\{14,15\},\{16\},\{17,18\},\{19\},\{20,21\}$, $\{22\},\{23,24\}\}$;

$U / I N D(D)=\{\{1,4,10,13,17,23,24\},\{2,15\},\{3,6\}$, $\{5,8\},\{7,20\},\{9\},\{11\},\{12\},\{14,18\},\{16,19\},\{21\}$, $\{22\}\}$.

The conditional attribute $c_{i}(i=1,2, \ldots, m)$ is successively removed, and the remaining conditional attributes are clustered using the aforementioned method, and the best classifications are as follows:

$\mathrm{U} / \mathrm{IND}\left(\mathrm{C}-\left\{c_{1}\right\}\right)=\{\{1,2,3\},\{4,5,6\},\{7,8,9\},\{10,11$, $12\},\{13,14,15\},\{16,17,18\},\{19,20,21\},\{22,23,24\}\}$;

$\mathrm{U} / \mathrm{IND}\left(\mathrm{C}-\left\{c_{2}\right\}\right)=\{\{1,10,16,22\},\{2,11,17,23\},\{3$, $12,18,24\},\{4,13,19\},\{5,14,20\},\{6,15,21\},\{7\},\{8\}$, $\{9\}\}$;

$\mathrm{U} / \mathrm{IND}\left(C-\left\{c_{3}\right\}\right)=\{\{1,4,7\},\{2,5,8\},\{3,6,9\},\{10$, $13\},\{11,14\},\{12,15\},\{16,19\},\{17,20\},\{18,21\},\{22\}$, $\{23\},\{24\}\}$.

The positive regions of the conditional attributes are as follows:

$$
\begin{aligned}
\operatorname{POS}_{\mathbf{C}}(\mathbf{D}) & =\{\mathbf{C}\}_{-}(\mathbf{D}) \\
& =\{1,4,7,10,13,16,19,22,23,24\}, \\
\operatorname{POS}_{\mathbf{C}\left\{c_{1}\right\}}(\mathbf{D}) & =\left\{\mathbf{C}-\left\{c_{1}\right\}\right\}_{-}(\mathbf{D})=\phi, \\
\operatorname{POS}_{\mathbf{C}-\left\{c_{2}\right\}}(\mathbf{D}) & =\left\{\mathbf{C}-\left\{c_{2}\right\}\right\}_{-}(\mathbf{D})=\{7,8,9\}, \\
\operatorname{POS}_{\mathbf{C}\left\{c_{3}\right\}}(\mathbf{D}) & =\left\{\mathbf{C}-\left\{c_{3}\right\}\right\}_{-}(\mathbf{D}) \\
& =\{10,13,16,19,22,23,24\} .
\end{aligned}
$$

The significance of the influencing factor $c_{i}$ on the splitting tensile strength loss rate $S G F\left(c_{i}, \mathbf{C}, \mathbf{D}\right)$ is calculated by equation (17):

$$
\begin{aligned}
\operatorname{SGF}\left(c_{1}, \mathbf{C}, \mathbf{D}\right) & =\gamma_{\mathbf{C}}(\mathbf{D})-\gamma_{\mathrm{C}\left\{c_{1}\right\}}(\mathbf{D}) \\
& =\frac{\left|P O S_{\mathbf{C}}(\mathbf{D})\right|}{|\mathbf{U}|}-\frac{\left|P O S_{\mathbf{C}\left\{c_{1}\right\}}(\mathbf{D})\right|}{|\mathbf{U}|}=\frac{10}{24}-\frac{0}{24}=\frac{10}{24}, \\
\operatorname{SGF}\left(c_{2}, \mathbf{C}, \mathbf{D}\right) & =\gamma_{\mathbf{C}}(\mathbf{D})-\gamma_{\mathbf{C}\left\{c_{2}\right\}}(\mathbf{D}) \\
& =\frac{\left|P O S_{\mathbf{C}}(\mathbf{D})\right|}{|\mathbf{U}|}-\frac{\left|P O S_{\mathbf{C}\left\{c_{2}\right\}}(\mathbf{D})\right|}{|\mathbf{U}|}=\frac{10}{24}-\frac{3}{24}=\frac{7}{24}, \\
\operatorname{SGF}\left(c_{3}, \mathbf{C}, \mathbf{D}\right) & =\gamma_{\mathbf{C}}(\mathbf{D})-\gamma_{\mathbf{C}\left\{c_{3}\right\}}(\mathbf{D}) \\
& =\frac{\left|P O S_{\mathbf{C}}(\mathbf{D})\right|}{|\mathbf{U}|}-\frac{\left|P O S_{\mathbf{C}\left\{c_{3}\right\}}(\mathbf{D})\right|}{|\mathbf{U}|}=\frac{10}{24}-\frac{7}{24}=\frac{3}{24} .
\end{aligned}
$$

Eventually, the weight of the influencing factor $c_{i}$ is as follows:

$$
\begin{aligned}
\mathbf{W}_{i} & =\frac{\operatorname{SGF}\left(c_{i}, \mathbf{C}, \mathbf{D}\right)}{\sum_{k=1}^{m} \operatorname{SGF}\left(c_{k}, \mathbf{C}, \mathbf{D}\right)} \\
& =\left(w_{c_{1}}, w_{c_{2}}, w_{c_{3}}\right)=(0.50,0.35,0.15) .
\end{aligned}
$$

Among the factors affecting the loss rate of the splitting tensile strength of HSPFRC, the number of F-T cycles has the most substantial influence, followed by the SF content, while the PF content has a relatively small impact. The corresponding weights are 0.50 (number of F-T cycles) $>0.35$ (SF content $)>0.15$ ( $\mathrm{PF}$ content). The relative significance of each influencing factor calculated by fuzzy rough set theory can effectively evaluate the degree of influencing factors affecting the durability of HSPFRC.

\section{Conclusions}

The combined effect of incorporating both SFs and PFs on the frost resistance of HSPFRC was studied in this work, and the relative significance of the environmental conditions and fiber contents was quantified by using fuzzy rough set theory. The major findings and conclusions are summarized as follows:

(1) An increase in the SF content can effectively improve the frost resistance of HSPFRC. Before $100 \mathrm{~F}-\mathrm{T}$ cycles, an increase in the SF content has a limited effect. However, after 500 F-T cycles, the frost resistance of HSPFRC is substantially improved, with the compressive strength and splitting tensile strength increasing by factors of approximately 5 and 4 , respectively, and the mass loss rate is reduced by more than 90\%; in addition, the flexural toughness can also increase rapidly as the SF content increases.

(2) The reinforcement effect of PFs on the performance of HSPFRC is relatively small compared with that of SFs. Similar to the addition of SFs, the mechanical properties of HSPFRC only slightly change with the variation in the PF content before $100 \mathrm{~F}-\mathrm{T}$ cycles. However, under continuous frost attack, an increase in the PF content can noticeably reduce the mass loss of concrete, with a reduction in S0.5P0.3 of almost $80 \%$ after $325 \mathrm{~F}-\mathrm{T}$ cycles. However, an increase in the PF content has a limited effect on improving the residual strength and flexural toughness.

(3) An appropriate content of hybrid fibers can substantially improve the frost resistance of HSPFRC when a low SF content (less than 1\%) is mixed with a high PF content (more than $0.2 \%$ ) or when a high SF content (more than $1 \%$ ) is mixed with a low PF content $(0.1 \%$ ). Considering the economy and workability of HSPFRC, S1.5P0.1 has an optimal fiber content, and its comprehensive properties are the best.

(4) The effect of the hybrid fiber content on the splitting tensile strength is greater than that on the 
compressive strength of HSPFRC. The RDEM is not suitable for evaluating the frost resistance of HSPFRC, which may be related to the F-T test regime and the influence of fibers on ultrasonic propagation.

(5) The flexural toughness of HSPFRC can be substantially improved after hybrid fibers are incorporated, and the selection of the concrete toughness evaluation method is closely related to the initial crack deflection and final deformation. The PCS and the modified JSCE flexural toughness coefficient are more suitable than CECS 13:2009 for evaluating the toughness of HSPFRC by taking the average stress of the midspan deflection as $L / 100$.

(6) Fuzzy rough set theory can objectively quantify the factors that affect the frost resistance of HSPFRC and directly reflect the degree of influence of each factor. In the presented work, the weights of the influencing factors are 0.50 (number of F-T cycles) $>0.35$ (SF content) $>0.15$ (PF content). That is, the number of F-T cycles can greatly affect the frost resistance of HSPFRC, while the inclusion of SFs with a high elastic modulus and better bond strength has a weaker influence, and the inclusion of PFs with a small elastic modulus and weak interface transition zone has a minimal impact.

\section{Data Availability}

The data used to support the findings of this study are available from the corresponding author upon request.

\section{Conflicts of Interest}

The authors declare that they have no conflicts of interest regarding the publication of this paper.

\section{Acknowledgments}

This work was funded by the National Natural Science Foundation of China (grant nos. 51808438 and 51878549) and the Independent Research and Development Project of State Key Laboratory of Green Building in Western China (grant no. LSZZ202016). The authors would like to gratefully acknowledge the support of the State Key Laboratory of Green buildings in Western China for providing the experimental platform.

\section{References}

[1] R. F. Zollo, "Fiber-reinforced concrete: an overview after 30 years of development," Cement and Concrete Composites, vol. 19, no. 2, pp. 107-122, 1997.

[2] Q. Wang, W. Sun, L. Guo, C. Gu, J. Zong, and S. Han, "Modeling chloride diffusion coefficient of steel fiber reinforced concrete under bending load," Advances in Civil Engineering, vol. 2018, Article ID 3789214, 6 pages, 2018.

[3] J. Thomas and A. Ramaswamy, "Mechanical properties of steel fiber-reinforced concrete," Journal of Materials in Civil Engineering, vol. 19, no. 5, pp. 385-392, 2007.
[4] Y. Qin, H. Wu, Y. Zheng, W. Wang, Z. Yi, and A. Si Larbi, "Microscopic texture of polypropylene fiber-reinforced concrete with x-ray computed tomography," Advances in Civil Engineering, vol. 2019, Article ID 2386590, 9 pages, 2019.

[5] M. Hsie, C. Tu, and P. S. Song, "Mechanical properties of polypropylene hybrid fiber-reinforced concrete," Materials Science and Engineering: A, vol. 494, no. 1, pp. 153-157, 2008.

[6] Y. Zhao, X. Sun, P. Cao et al., "Mechanical performance and numerical simulation of basalt fiber reinforced concrete (BFRC) using double-k fracture model and virtual crack closure technique (VCCT)," Advances in Civil Engineering, vol. 2019, Article ID 5630805, 15 pages, 2019.

[7] V. Dhand, G. Mittal, K. Y. Rhee, S.-J. Park, and D. Hui, "A short review on basalt fiber reinforced polymer composites," Composites Part B: Engineering, vol. 73, pp. 166-180, 2015.

[8] H. Tanyildizi and C. Vipulanandan, "Prediction of the strength properties of carbon fiber-reinforced lightweight concrete exposed to the high temperature using artificial neural network and support vector machine," Advances in Civil Engineering, vol. 2018, Article ID 5140610, 10 pages, 2018.

[9] M. Atiyeh and E. Aydin, "Carbon-fiber enriched cementbased composites for better sustainability," Materials, vol. 13, no. 8, p. 1899, 2020.

[10] M. A. Rashid, M. A. Mansur, and P. Paramasivam, "Behavior of aramid fiber-reinforced polymer reinforced high strength concrete beams under bending," Journal of Composites for Construction, vol. 9, no. 2, pp. 117-127, 2005.

[11] A. B. Kizilkanat, N. Kabay, V. Akyüncü, S. Chowdhury, and A. H. Akça, "Mechanical properties and fracture behavior of basalt and glass fiber reinforced concrete: an experimental study," Construction and Building Materials, vol. 100, pp. 218-224, 2015.

[12] Y. Zheng, X. Wu, G. He et al., "Mechanical properties of steel fiber-reinforced concrete by vibratory mixing technology," Advances in Civil Engineering, vol. 2018, Article ID 9025715, 11 pages, 2018

[13] K. Kawashima, R. Zafra, T. Sasaki, K. Kajiwara, and M. Nakayama, "Effect of polypropylene fiber reinforced cement composite and steel fiber reinforced concrete for enhancing the seismic performance of bridge columns," Journal of Earthquake Engineering, vol. 15, no. 8, pp. 1194-1211, 2011.

[14] X. Xi and S. Yang, "Investigating the spatial development of corrosion of corner-located steel bar in concrete by x-ray computed tomography," Construction and Building Materials, vol. 221, pp. 177-189, 2019.

[15] D.-Y. Yoo, M. J. Kim, S.-W. Kim, and J.-J. Park, "Development of cost effective ultra-high-performance fiber-reinforced concrete using single and hybrid steel fibers," Construction and Building Materials, vol. 150, pp. 383-394, 2017.

[16] P. Smarzewski and M. Aniello, "Flexural toughness of highperformance concrete with basalt and polypropylene short fibers," Advances in Civil Engineering, vol. 2018, Article ID 5024353, 8 pages, 2018.

[17] S. H. Park, D. J. Kim, G. S. Ryu, and K. T. Koh, "Tensile behavior of ultra high performance hybrid fiber reinforced concrete," Cement and Concrete Composites, vol. 34, no. 2, pp. 172-184, 2012.

[18] D. L. Nguyen, D. J. Kim, G. S. Ryu, and K. T. Koh, "Size effect on flexural behavior of ultra-high-performance hybrid fiberreinforced concrete," Composites Part B: Engineering, vol. 45, no. 1, pp. 1104-1116, 2013.

[19] J. Blunt, G. Jen, and C. P. Ostertag, "Enhancing corrosion resistance of reinforced concrete structures with hybrid fiber 
reinforced concrete," Corrosion Science, vol. 92, pp. 182-191, 2015.

[20] L. Xu, L. Huang, Y. Chi, and G. Mei, “Tensile behavior of steelpolypropylene hybrid fiber-reinforced concrete," ACI Materials Journal, vol. 113, no. 2, pp. 219-229, 2016.

[21] F. Köksal, O. Gencel, B. Unal, and M. Y. Durgun, "Durability properties of concrete reinforced with steel-polypropylene hybrid fibers," Science and Engineering of Composite Materials, vol. 19, no. 1, pp. 19-27, 2012.

[22] F. Aslani and S. Nejadi, "Self-compacting concrete incorporating steel and polypropylene fibers: compressive and tensile strengths, moduli of elasticity and rupture, compressive stress-strain curve, and energy dissipated under compression," Composites Part B: Engineering, vol. 53, pp. 121-133, 2013.

[23] P. Smarzewski and D. Barnat-Hunek, "Fracture properties of plain and steel-polypropylene-fiber-reinforced high-performance concrete," Materiali in Tehnologije, vol. 49, no. 4, pp. 563-571, 2015.

[24] Y. Chi, M. Yu, L. Huang, and L. Xu, "Finite element modeling of steel-polypropylene hybrid fiber reinforced concrete using modified concrete damaged plasticity," Engineering Structures, vol. 148, pp. 23-35, 2017.

[25] A. Saradar, B. Tahmouresi, E. Mohseni, and A. Shadmani, "Restrained shrinkage cracking of fiber-reinforced highstrength concrete," Fibers, vol. 6, no. 1, 2018.

[26] V. Afroughsabet and T. Ozbakkaloglu, "Mechanical and durability properties of high-strength concrete containing steel and polypropylene fibers," Construction and Building Materials, vol. 94, pp. 73-82, 2015.

[27] H. Cai and X. Liu, "Freeze-thaw durability of concrete: ice formation process in pores," Cement and Concrete Research, vol. 28, no. 9, pp. 1281-1287, 1998.

[28] Japan Society of Civil Engineers, "Method of test for flexural strength and flexural toughness of fiber reinforced concrete (SF-4)," in Japan Society of Civil Engineers, pp. 58-66, Japan Society of Civil Engineers, Tokyo, Japan, 1984.

[29] N. Banthia and J. Trottier, "Test methods for flexural toughness characterization of fiber reinforced concrete: some concerns and a proposition," ACI Materials Journal, vol. 92, no. 1, pp. 48-57, 1995.

[30] China Engineering Construction Standardization Association, "Standard test methods for fiber reinforced concrete," in China Engineering Construction Standardization AssociationChina Planning Press, Beijing, China, 2010.

[31] Ministry of Construction of the PRC, "Standard test method for mechanical properties on ordinary concrete GB/T 500812019," in Ministry of Construction of the People's Republic of ChinaChina Architecture \& Building Press, Beijing, China, 2019.

[32] Ministry of Construction of the PRC, "Standard for test methods of long-term performance and durability of ordinary concrete GB/T 50082-2009," in Ministry of Construction of the People's Republic of ChinaChina Architecture \& Building Press, Beijing, China, 2009.

[33] F. D. Lydon and M. Iacovou, "Some factors affecting the dynamic modulus of elasticity of high strength concrete," Cement and Concrete Research, vol. 25, no. 6, pp. 1246-1256, 1995.

[34] C. Jianguo, L. Jinyu, L. Lin et al., "Study on frost resistance of high strength concrete," Journal of Building Materials, vol. 2, no. 4, pp. 292-297, 1999.

[35] B. Mu, C. Meyer, and S. Shimanovich, "Improving the interface bond between fiber mesh and cementitious matrix,"
Cement and Concrete Research, vol. 32, no. 5, pp. 783-787, 2002.

[36] O. Karahan and C. D. Atiş, "The durability properties of polypropylene fiber reinforced fly ash concrete," Materials \& Design, vol. 32, no. 2, pp. 1044-1049, 2011.

[37] Y. Choi and R. L. Yuan, "Experimental relationship between splitting tensile strength and compressive strength of GFRC and PFRC," Cement and Concrete Research, vol. 35, no. 8, pp. 1587-1591, 2005.

[38] X. Xi, S. Yang, and C.-Q. Li, "A non-uniform corrosion model and meso-scale fracture modelling of concrete," Cement and Concrete Research, vol. 108, pp. 87-102, 2018.

[39] G. Danying, Z. Liangping, F. Hu, and Z. Shunbo, "Flexural toughness and its evaluation method of steel fiber reinforced concrete," Journal of Building Materials, vol. 17, no. 5, pp. 783-789, 2014.

[40] J. Xie and C. Ping, Fuzzy Mathematics Method and Applications, Huazhong University of Science \& Technology Press, Wuhan, China, 4th edition, 1995.

[41] S. Miyamoto, H. Ichihashi, K. Honda, and H. Ichihashi, Algorithms for Fuzzy Clustering, Springer, Berlin, Germany, 2018.

[42] Z. Pawlak, "Rough sets and intelligent data analysis," Information Sciences, vol. 147, no. 1-4, pp. 1-12, 2002. 